Max-Planck-Institut für demografische Forschung

Max Planck Institute for Demographic Research

Konrad-Zuse-Strasse 1 - D-18057 Rostock - GERMANY

Tel +49 (0) 3812081 - 0; Fax +49 (0) 3812081 - 202;

http://www.demogr.mpg.de

MPIDR WORKING PAPER WP 2010-029

OCTOBER 2010

\title{
From Transfers to Capital: \\ Analyzing the Spanish Demand for Wealth using NTA
}

\author{
Miguel Sánchez Romero (msanchez@demogr.mpg.de) \\ Concepción Patxot \\ Elisenda Rentería \\ Guadalupe Souto
}

This working paper has been approved for release by: Michaela Kreyenfeld (kreyenfeld@demogr.mpg.de), Acting Deputy Head of the Laboratory of Economic and Social Demography.

(C) Copyright is held by the authors.

Working papers of the Max Planck Institute for Demographic Research receive only limited review. Views or opinions expressed in working papers are attributable to the authors and do not necessarily reflect those of the Institute. 


\title{
From Transfers to Capital: Analyzing the Spanish Demand for Wealth using NTA*
}

\author{
Miguel Sánchez Romero ${ }^{\dagger 1}$, Concepción Patxot ${ }^{2}$, Elisenda Rentería ${ }^{3}$, \\ and Guadalupe Souto ${ }^{4}$ \\ ${ }^{1}$ Max Planck Institute for Demographic Research \\ ${ }^{2}$ Centre d'Anàlisi Econòmica i de les Polítiques Socials (CAEPS), Universitat de \\ Barcelona and Instituto de Estudios Fiscales \\ ${ }^{3}$ Universidade Federal de Minas Gerais, Belo Horizonte \\ ${ }^{4}$ Departamento de Economía Aplicada, Universidad Autónoma de Barcelona
}

October 1, 2010

\begin{abstract}
Inter- and intra-family transfers are a very important part of our daily economic activity. These transfers, whether familial or public, may influence our economic decisions to the same extent that financial markets do. In this paper, we seek to understand how the Spanish stock of capital will evolve if the set of intergenerational transfers observed in year 2000 are maintained in the future. With that aim in mind, we have implemented a general equilibrium overlapping generations model with realistic public and familial transfers drawn from the National Transfer Accounts project (NTA). Given that familial transfers go from parents to children, and public transfers go from children to parents, we show that the Spanish baby boom and baby bust will make the second demographic dividend temporary, and that welfare will be reduced from 2040 onwards.
\end{abstract}

JEL Classification Numbers: D58; J11; H53; H69

Keywords: Second demographic dividend; Transfers; Computable general equilibrium.

${ }^{*}$ We are extremely thankful to Ronald D. Lee, Andrew Mason, Gretchen Donehower, and David Reher for giving us very useful comments, suggestions, and ideas. We have received helpful research assistance from Ignacio Moral and language editing from Miriam Hils Cosgrove. We are also grateful to the Center on Economics and Demography of Aging (CEDA) and the Department of Demography at UC Berkeley for their hospitality. This work received institutional support from the Spanish Science and Technology System (Projects N ECO2009-10003 and ECO2008-04997/ECON), the Catalan Government Science Network (Projects No SGR2009-600 and SGR2009-359 as well as from XREPP- Xarxa de referència en Economia i Política Públiques), the Fulbright Commission (reference \# 2007-0445), and the Max Planck Society.

${ }^{\dagger}$ Corresponding Author: Konrad-Zuse-Str. 1, 18057 Rostock, Germany. Phone: +49 (381) 2081-174 Fax: +49 (381) 2081-474, Email: msanchez@demogr.mpg.de 


\section{Introduction}

The Spanish economy faces one of the most dramatic population aging processes of all the developed countries. According to Eurostat population projections, the old-age dependency ratio in Spain will go from $24.55 \%$ in year 2007 to $65 \%$ in year 2050 . Will the sharp increase in this ratio be burdensome for future workers? The answer to this question is: "Not necessarily". In contrast to dependent children, retirees may finance their consumption with their own capital. The increasing number of retirees with savings, followed by smaller cohorts of workers, may lead to capital deepening, which is also known in the economic literature as the second demographic dividend (Mason and Lee, 2006). As a result, workers are able to finance retirement benefits more easily, since they become more productive, even when human capital investments remain unchanged. However, unless the necessary incentives for accumulating capital are in place, there will not be a second demographic dividend, and the economic effects will be negative instead of positive.

Mainly in response to the decline in savings rate after the postwar period in the U.S., the literature has studied extensively the mechanisms for stimulating the accumulation of capital(Gokhale et al., 1996). We know from this literature that population aging, which is the combined result of mortality reduction for old age groups followed by a decrease in fertility, should a priori lead to a greater capital accumulation. Indeed, assuming the retirement age remains constant, increases in life expectancy after retirement should boost the motivation to save for retirement, while smaller family sizes should reduce overall childrearing costs to parents, thereby increasing the ability to save. Nevertheless, non-marketable transfers might either increase or decrease savings, boosting or offsetting the positive economic effects of population aging. The net effect depends on the difference between the size of the transfers individuals will receive, and how much they will have to pay over the course of their remaining lifespan (Willis, 1988); or, equivalently, how much wealth individuals will demand to satisfy their consumption needs relative to the existing stock of capital (Lee, 1994; Bommier and Lee, 2003). If individuals expect to receive more transfers than they give during their lifetimes, they will deplete capital. For this reason, models that do not introduce transfers might lead to different results (Kotlikoff and Summers, 1981). In order to explain the accumulation of capital over time, it is therefore critical to specify current and future population characteristics, marketable transfers, and non-marketable public and private transfers.

In this paper, we aim to understand how the Spanish stock of capital will evolve if the set of intergenerational transfers observed in year 2000 are maintained in the future. To control for changes in production factor prices, we implement an overlapping generations model, adding realistic public and familial transfers by single years of age. In order to keep the 
observed transfer profiles, we take them as given by assuming non-perfectly altruistic agents. Thus far, the implementation of OLG growth models to elaborate the stock of wealth has been difficult due to the lack of age profiles for non-marketable variables. To bridge this gap, the National Transfer Accounts Project (NTA) has made available estimates of marketable and non-marketable inter-age flows that are consistent with National Income and Product Accounts (NIPA). ${ }^{1}$ A first attempt to derive age-specific information was made using Generational Accounts (GA), which were developed to assess the fiscal burden that current generations are placing on future generations (Auerbach et al., 1991). The GA provides information on intergenerational public transfers, but it lacks information on familial transfers, which is crucial for understanding the accumulation of savings in OLG models (Sanchez-Romero, 2009). To complement GA, NTA has developed a "cross-sectional" accounting framework for analyzing how public and private consumption are financed over the life cycle.

This work is the first general equilibrium OLG model that uses the NTA data. Because the NTA database provides inter-age flows of both public and familial transfers, we are able to produce both market and non-market transfers by age and over time that are consistent with the OLG and the NTA models, and, therefore, with National Accounts. To take advantage of all the rich demographic information by single years of age, we have realistically modeled the Spanish demography (see Appendix A.1 for a detailed explanation of the methodology). The calibration procedure has been developed so as to simultaneously target the NTA age profiles, the main Spanish macroeconomic statistics, and the Spanish government budget in year $2000 .^{2}$ Hence, this paper differs from other general equilibrium OLG models applied to the Spanish economy in that we introduce the whole set of familial and public transfers by age in a realistic fashion (Ríos-Rull, 2001; Rojas, 2005; Díaz-Giménez and Díaz-Saavedra, 2009; Sanchez-Martin, 2010).

In line with previous literature, we show how population aging will cause an increase in payroll taxes and a subsequent decrease in disposable income. We estimate that, in 2040, the decrease in disposable income will be $17.1 \%$, against an assumed $1.26 \%$ annual increase in labor-augmenting technological progress. Strikingly, we also find that aggregate consumption and the stock of effective capital will increase significantly up to 2040. However, this positive economic scenario will be temporary. Indeed, we found that the additional accumulation of effective capital will be depleted, first because baby boomers will not save enough, due to the generous pensions they can expect to receive relative to what they have contributed; and, second, because the baby bust generation will consume too much, since they will not have an incentive to save given the large amounts of inter-vivos transfers that they

\footnotetext{
${ }^{1}$ National Transfer Account database (NTA), http://www.ntaccounts.org.

${ }^{2}$ For space sake we have opted for placing the calibration procedure in Appendix A.
} 
expect to receive from their parents.

The remainder of the paper is divided into five parts. Given the novelty of the NTA database and the peculiarities of its accounting strategy, we devote Sections 2 and 3 to introducing the NTA methodology in a simple four overlapping generations setup. The former section presents the similarities between the standard flow budget constraint used in OLG models and the one used in NTA, and shows how to transform one into the other. The latter section introduces the concepts of the demand for wealth, which includes transfers wealth. Section 4 shows the specific features of our general equilibrium model with 101 overlapping generations. Section 5 presents our simulation results for the Spanish economy. Finally, we place the calibration of the model, as well as the algorithm, in the Appendix.

\section{OLG meets NTA}

The overlapping generations model developed by Samuelson (1958) and Diamond (1965) is currently the theoretical workhorse for analyzing the intergenerational trading of goods and services. Its micro-foundation lies in the life cycle theory of saving, and the model enables us to examine outcomes by age in both a cross-sectional and a longitudinal fashion. In building this simulation model, we make use of the standard Samuelson-Diamond model, and we introduce the necessary arrangements for transforming the flow budget constraint, which is frequently used in the OLG models, into the NTA flow identity. ${ }^{3}$

The NTA identity aims to reflect the reallocation of economic resources across different age groups to finance the life cycle deficit (LCD). We define LCD as the difference between consumption (public and private) and gross labor income. ${ }^{4}$ We will demonstrate below that this definition is adequate for analyzing the mechanism through which resources are allocated, i.e., marketable and non-marketable transfers; as well as the institutions involved in the transfers, such as households, the public sector, or markets.

For simplicity, in Sections 2 and 3 we assume a stable population comprised of four generations, and a closed economy in a steady-state equilibrium.

\footnotetext{
${ }^{3}$ See Willis (1988) for a first attempt to include exogenous family transfers in the OLG framework. See also Lee (1994) for an application estimating the size of transfer and real wealth in the United States.

${ }^{4}$ This definition of life cycle deficit differs from Kotlikoff and Summers (1981). Recall that, by estimating savings from lifetime income and (only) private consumption data, the authors indirectly measured the relevance of intergenerational transfers on capital accumulation; see Lee (1994).
} 


\subsection{OLG flow budget constraints}

We assume the first and last cohorts are children and retirees, respectively, and that parents and children are one generation apart. We assume that children leave their parents' home when they belong to generation one, setting up their own household. After the children are settled, the parents do not directly finance their children's consumption needs, although they may continue to transfer economic resources.

Let asset holdings of a representative individual of age $x$ be $a_{x}$. At any given age $x \in\{1,2,3\}$, asset holding at age $x+1$ is the result of the capitalization, net of taxes, of previous and inherited asset holdings, plus net earnings, plus net received transfers, less consumption of the economic unit at market prices. We may assume that, realistically, children do not make any economic decisions. Therefore, parents finance children's consumption needs until they become adults. Assuming that both market and non-market exchanges occur at the end of the period, asset holdings for each adult generation may be written as follows:

$$
\begin{array}{r}
a_{2}=\left(1+\left(1-\tau^{i}\right) r\right)\left(a_{1}+h_{1}\right)+\left(1-\tau^{i}\right)\left(1-\tau^{s s}\right) y_{l 1}+\phi_{1}-\left(1+\tau^{p}\right) \lambda_{1} c_{1}, \\
a_{3}=\left(1+\left(1-\tau^{i}\right) r\right)\left(a_{2}+h_{2}\right)+\left(1-\tau^{i}\right)\left(1-\tau^{s s}\right) y_{l_{2}}+\phi_{2}-\left(1+\tau^{p}\right) \lambda_{2} c_{2}, \\
a_{4}=\left(1+\left(1-\tau^{i}\right) r\right)\left(a_{3}+h_{3}\right)+\left(1-\tau^{i}\right) b_{3}+\phi_{3}-\left(1+\tau^{p}\right) \lambda_{3} c_{3}
\end{array}
$$

where $c_{x}$ is consumption at age $x, r$ is the (real) interest rate, $\left\{\tau^{i}, \tau^{s s}, \tau^{p}\right\}$ is the subset of personal income, payroll, and consumption taxes levied directly on households, $y_{l_{x}}$ is the (gross) wage at age $x, h_{x}$ is the inheritance received at age $x, \phi_{x}$ is the net intervivos family transfers at age $x, b_{x}$ is public benefits received at age $x$, and $\lambda_{x}$ is the number of equivalent adult consumers in the household supported by household head age $x$.

Flow budget constraints (1)-(3) are, unfortunately, not adequate for analyzing transfers. First, they do not include all transfers between individuals and the government; e.g., information about public consumption such as public education, publicly provided health care, public infrastructure, etc. Second, they do not include transfers between firms and the government; e.g., corporate tax and production subsidies.

\subsection{The NTA accounting strategy}

In general, children and retirees consume more than they produce, whereas production is higher than consumption at prime working ages. The surplus generated by workers is partly stored in the financial sector as a buffer stock; partly levied by the government to provide goods, services, and benefits; and partly transferred within and outside the household to support the consumption of other age groups. In order to illustrate explicitly these life cycle decisions, NTA split each flow budget constraint into four accounting items: i) the life cycle deficit (LCD), ii) the asset-based reallocation (ABR), 
iii) public transfers (TG), and iv) familial transfers (TF). The NTA fundamental equation is then given as

$$
\mathrm{LCD}_{x}=\mathrm{ABR}_{x}+\mathrm{TG}_{x}+\mathrm{TF}_{x} .
$$

Each accounting item represents a flow variable, where positive (negative) values are associated to net recipients (givers). First, LCD measures the difference between (public and private) goods and services consumed, and the value of goods and services produced by age. Thus, a cohort who produce more (less) than they consume will have a negative (positive) LCD. Second, transfers are divided into public and private: TG stands for public and TF for private net transfers received directly or indirectly by individuals. ${ }^{5}$ Since total transfers given (outflow) equals total transfers received (inflow), at an aggregate level in a closed economy, both public and private transfers must net to zero; i.e. ${ }^{6}$

$$
\begin{aligned}
& \sum_{x=0}^{3} \mathrm{TG}_{x} N_{x+1}=0 \\
& \sum_{x=0}^{3} \mathrm{TF}_{x} N_{x+1}=0 .
\end{aligned}
$$

In order to satisfy Equation (5), we impute public consumption $(g)$ and corporate taxes to individuals. Hence note that TG is then the flip side of GA. To keep the formulae simple, we assume that corporate taxes are paid by individuals according to their asset holdings,

$$
\tau^{c} \frac{r+\delta}{1-\tau^{c}} K=\tau^{c} \frac{r+\delta}{1-\tau^{c}} \sum_{x=1}^{3}\left(a_{x}+h_{x}\right) N_{x+1}
$$

where $\tau^{c}$ is the corporate tax rate, $\delta$ is the capital depreciation rate, and $h_{x}$ is the bequests received at age $x .^{7}$ Similarly, to satisfy Equation (6), it is necessary to introduce the bequest given (outflow) in the flow budget constraint, since at an aggregate level, bequests received must be balanced by bequests given (see Equations (12)-(13) below).

\footnotetext{
${ }^{5}$ As NTA assumes the individual is the fundamental unit, net transfers received by firms from the government are also imputed to individuals.

${ }^{6}$ In an open economy the sum of all private transfers is equal to the value of net transfers with the rest of the world.

${ }^{7}$ Since parents and children are one generation apart and transfers occur at the end of the period, the inheritance at age $x$ is

$$
h_{x}= \begin{cases}a_{x+1} q_{x+1} & \text { for } x=\{1,2\}, \\ 0 & \text { for } x=3 .\end{cases}
$$

Where $q_{x}$ is the probability of dying from age $x$ to age $x+1$. See Appendix A.7.2 for a more realistic inheritance profile.
} 
Finally, ABR measures the use of financial and real assets to finance current and future LCDs, which is equal to asset income less savings. Asset income can be decomposed into the interest gained by those who survived up to the end of the period, and that of those who died during the period. ${ }^{8}$ Another important feature of the NTA accounting framework is that it is consistent with national income and product accounts (NIPA), and, thus, assuming a closed economy, the sum across age of the life cycle deficit gives

$$
\underbrace{\sum_{x=0}^{3} \operatorname{LCD}_{x} N_{x+1}}_{C+G-y_{l} L}=\underbrace{\sum_{x=0}^{3} \operatorname{ABR}_{x} N_{x+1}}_{r K-S}+\underbrace{\sum_{x=0}^{3}\left(\mathrm{TG}_{x}+\mathrm{TF}_{x}\right) N_{x+1}}_{0},
$$

which, by rearranging the terms, is equal to the market-clearing condition

$$
C+G+S=r K+y_{l} L
$$

where $C$ and $G$ are aggregate private and public consumption, $S$ is the aggregate net savings, $K=\sum_{x=1}^{3} a_{x} N_{x}$ is the stock of physical capital, and $L=\sum_{x=1}^{2} N_{x}$ is the labor force.

\subsection{NTA flow budget constraints}

The accumulation of capital over time, and thus economic growth, depends on how much wealth individuals demand relative to the existing stock of capital. The demand for wealth is determined not only by adults (decisionmakers) but also by children (non-decision-makers). In overlapping generations models, the budget constraint of a non-decision-maker is not explicitly modeled. Instead, children's resources and expenditures are taken into account in the budget constraints of adults. As a result, flow budget constraints, such as (1)-(3), turn out to be a poor accounting framework for analyzing the effect that transfers to children have on economic growth. To fix this problem, in this subsection we introduce the NTA flow budget constraint and its main components for each cohort, regardless whether they make decisions.

We start with the assumption that children do not work until they become adults. Consequently, their LCD is positive and equal to private and public consumption. Provided that children neither hold assets, so that their $\mathrm{ABR}$ are equal to zero; nor make any economic decisions, their life cycle deficit is only financed through private and public transfers, as shown below

$$
\underbrace{c_{0}+g_{0}}_{\mathrm{LCD} 0}=\underbrace{g_{0}}_{\mathrm{TG}_{0}}+\underbrace{\theta_{0} c_{1}}_{\mathrm{TF}_{0}}
$$

\footnotetext{
${ }^{8}$ Current estimates of NTA profiles do not explicitly report bequests given. As a consequence, the ABR profile implicitly includes bequests received $(h)$. This fact implies that if bequest motive is important, ABR will be higher than expected at younger ages.
} 
where $\theta_{0}$ is the consumption of children relative to the consumption of an adult who belongs to generation one. ${ }^{9}$ Values for $g_{0}$ and $\theta_{0}$ in Spain in the year 2000 are shown in Figure 12 in Appendix A.4. Figure 12 suggests that transfers to a child account for more than $50 \%$ of the consumption of an adult between the ages 30 and 49. Unfortunately, many economic models analyzing the accumulation of capital lack this information, and thus their consumption and saving profiles ultimately lead to flawed results.

Equation (12) is the NTA flow budget constraint of a worker. In general, the surplus at working ages $(\mathrm{LCD}<0)$ will be used to finance other cohorts' life cycle deficits, mainly through transfers. From a public perspective, this means that workers pay more taxes than the sum of public expenditures and benefits received. Hence, workers are net providers of public goods and services to other age groups. From the familial perspective, individuals at prime working ages raise their children, and, if there are no public pensions, they also finance the consumption of retirees. Thus, both public and familial transfers have an important effect on the accumulation of capital. Assuming selfish individuals, we will have the following effects. On the one hand, transfers given to other age groups reduce savings at prime working ages. On the other hand, transfers may affect saving by changing the level of consumption.

The difference between LCD and the sum of public and private transfers is the ABR. According to the life cycle theory of saving, we should expect to see negative values at the beginning of the working period, and positive values when individuals get closer to retirement. Nevertheless, the ABR profile could change depending upon the importance of transfers to children and retirees, as well as the altruistic behavior towards other cohorts.

$$
\begin{gathered}
\underbrace{c_{x}+g_{x}-y_{l}}_{\mathrm{LCD}_{x}}=\underbrace{r a_{x}-s_{x}+(1+r) \frac{q_{x}}{p_{x}} a_{x}}_{\mathrm{ABR}_{x}} \\
+\underbrace{g_{x}-\tau^{i}\left(r\left(a_{x}+h_{x}\right)+\left(1-\tau^{s s}\right) y_{l x}\right)-\tau^{s s} y_{l x}-\tau^{p} \lambda_{x} c_{x}-\tau^{c} \frac{r+\delta}{1-\tau^{c}}\left(a_{x}+h_{x}\right)}_{\mathrm{TG}_{x}} \\
+\underbrace{(1+r) h_{x}-(1+r) \frac{q_{x}}{p_{x}} a_{x}+\phi_{x}-\left(\lambda_{x}-1\right) c_{x}}_{\mathrm{TF}_{x}}
\end{gathered}
$$

where $p_{x}$ is the probability of surviving from age $x$ to age $x+1$ and $q_{x}$ its complementary; that is, $p_{x}+q_{x}=1$.

Retirees have a positive LCD since they do not work. But, unlike children, retirees' positive LCD can be financed not only through public and pri-

\footnotetext{
${ }^{9} \mathrm{~A}$ more realistic child rearing costs, as that introduced in Section 4, depends on the average consumption of the parent.
} 
vate transfers, but also through assets. The importance of assets in Equation (13) is key for analyzing the effect that population aging has on the accumulation of capital. The economic effect is positive whenever the proportion of ABR financing LCD is high, since it enhances the second demographic dividend. But the economic effect turns negative when the proportion of ABR financing LCD is small, since the second demographic dividend becomes temporary. However, there are other important reasons for financing the LCD of the elderly through transfers, such as the reduction of inequality and the improvement of welfare in response to market inefficiencies, like borrowing constraints (Diamond, 1977).

$$
\begin{array}{r}
\underbrace{c_{3}+g_{3}}_{\mathrm{LCD}_{3}}=\underbrace{r a_{3}-s_{3}+(1+r) \frac{q_{3}}{p_{3}} a_{3}}_{\mathrm{ABR}_{3}} \\
+\underbrace{g_{3}+b_{3}-\tau^{i}\left(r\left(a_{3}+h_{3}\right)+b_{3}\right)-\tau^{p} \lambda_{3} c_{3}-\tau^{c} \frac{r+\delta}{1-\tau^{c}}\left(a_{3}+h_{3}\right)}_{\mathrm{TG}_{3}} \\
+\underbrace{(1+r) h_{3}-(1+r) \frac{q_{3}}{p_{3}} a_{3}+\phi_{3}-\left(\lambda_{3}-1\right) c_{3}}_{\mathrm{TF}_{3}} .
\end{array}
$$

Except for those countries where elderly parents cohabit with their children (e.g., Taiwan, Thailand, and, to a lesser extent, South Korea), cross-country comparisons suggest that assets and public transfers dominate familial transfers in the financing of retirees' LCD (Lee and Mason, 2010b). Lee and Mason (2010b) have also found that, in countries where the pension benefit system is generous, ABR represents less than $40 \%$ of the LCD, and vice versa. However, this does not mean that the retirees are dissaving. On the contrary, according to the Spanish NTA results, the elderly are saving to make inter-vivos, and, most likely, post-mortem transfers. Thus, provided retirees' children are not part of the household, retirees make downward inter-household transfers, i.e, $\phi_{3}<0$, and thus $\phi_{1}, \phi_{2}>0$.

\section{From transfers to capital}

This section is devoted to explaining how changes in transfers affect the accumulation of capital. According to the life cycle model, asset holdings at any given age (or demand for real wealth) is the present value of the remaining lifetime expenditures, less the present value of the remaining lifetime income (including transfers). The demand for life cycle wealth at any given age is, by contrast, the present value of the remaining lifetime of own consumption (public and private), less the present value of the remaining marginal product of labor. Both demands are easily formulated using the 
NTA framework. The demand for real wealth at age $x$ can be calculated as the present value, survival weighted, of the remaining ABR profiles

$$
a_{x}=\sum_{s=x}^{3} \mathrm{ABR}_{s} \prod_{z=x}^{s} \frac{p_{z}}{1+r}=\sum_{s=x}^{3}\left((1+r) \frac{1}{p_{s}} a_{s}-a_{s+1}\right) \prod_{z=x}^{s} \frac{p_{z}}{1+r},
$$

with $a_{4}=0$, whereas the demand for life cycle wealth is derived through LCD profiles,

$$
w_{x}=\sum_{s=x}^{3} \operatorname{LCD}_{s} \prod_{z=x}^{s} \frac{p_{z}}{1+r}=\sum_{s=x}^{3}\left(c_{s}+g_{s}-y_{l_{s}}\right) \prod_{z=x}^{s} \frac{p_{z}}{1+r} .
$$

Note that the discount factor naturally arises from discounting the NTA flow budget constraints of the cohort. Equation (15) is related to (14) using the NTA identity (4) as follows:

$$
w_{x}=a_{x}+\sum_{s=x}^{3} \eta_{s} \prod_{z=x}^{s} \frac{p_{z}}{1+r}=a_{x}+t_{x} .
$$

where $\eta_{s}$ is total transfers at age $s, \mathrm{TG}_{s}+\mathrm{TF}_{s}$, and $t_{x}$ is the demand for transfer wealth or the present value, evaluated at age $x$, of the remaining lifetime public and familial transfers.

At an aggregate level, the demand for life cycle wealth can be obtained by multiplying $w_{x}$ by the number of people at each age. Summing Equation (16) across age gives the aggregate demand for life cycle wealth,

$$
W=\sum_{x=0}^{3} w_{x} N_{x}=\sum_{x=0}^{3} a_{x} N_{x}+\sum_{x=0}^{3} t_{x} N_{x}=K+T,
$$

where $K$ is the aggregate supply of capital by households (or aggregate demand for real wealth) and $T$ is the aggregate demand for transfer wealth. ${ }^{10}$ As a particular case, we have that $K$ is the stock of physical capital if, and only if, the economy is closed; otherwise, $K$ will be asset holdings by people in the country.

The comparison between the aggregate demand for real wealth $(K)$ and the aggregate demand for life cycle wealth $(W)$ gives us insight into the excess, or deficit, of aggregate lifetime consumption over financial and human capital, ${ }^{11}$ where human capital is defined as the present value, survival

\footnotetext{
${ }^{10}$ For the definition of $T$ and $K$ we follow Willis (1988) and Lee (1994).

${ }^{11}$ The demand for life cycle wealth by an individual at age $x$ equals the present value, survival weighted, of the stream of public and private consumption less human capital. Let the present value of consumption and human capital be denoted by $\tilde{c}$ and $\tilde{H}_{x}$. Then, the intertemporal budget constraint is given by

$$
w_{x}=\tilde{c}_{x}-\tilde{H}_{x}=a_{x}+t_{x} \Rightarrow \tilde{c}_{x}=\tilde{H}_{x}+a_{x}+t_{x} .
$$

Thus, for $\tilde{c}_{x}>(<) \tilde{H}_{x}+a_{x}$ it is necessary that $t_{x}>(<) 0$.
} 
weighted, of the stream of gross salaries. If $W$ is greater than $K$, the current population are on average, net receivers of transfers $(T>0)$, which allow them to have a higher rate of consumption, assuming the stock of capital remains the same. The opposite is also true when $T<0$. Whether $T$ is equal to, greater than, or lower than zero depends upon both demographics and institutional arrangements. See Figure 1 for an illustration. Panel 1(a) shows the demands for total and real wealth under two different populations with similar institutional arrangements, while by holding the population age structure constant, Panel 1(b) shows an economy with two different sets of transfers.

In Panel 1(a), the demands for real and life cycle wealth of a population with high fertility and high mortality (pre-demographic transition) are represented by the small letters $s s$ and $w w$. Meanwhile, the capital letters $S S$ and $W W$ stand for the demands for real and life cycle wealth of a population with low fertility and low mortality (post-demographic transition).

Assuming that production technology does not change over time, the market interest rate is set when the demand for capital by firms, or curve $D D$, crosses the aggregate demand for real wealth by individuals; these are points $a$ or $b$, depending upon the demographic scenario. For any given interest rate, we can see that the demand for real wealth $S S$ is always greater than $s s$. This is because, in the former economy, individuals live longer and are motivated to save more for retirement. As a result, assuming the set of transfers does not change, economies with longer life expectancies will experience lower interest rates and accumulate more effective capital.

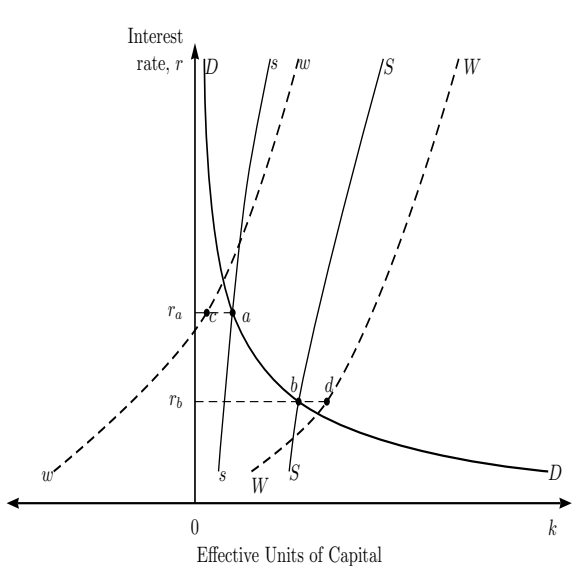

(a) Demographic changes

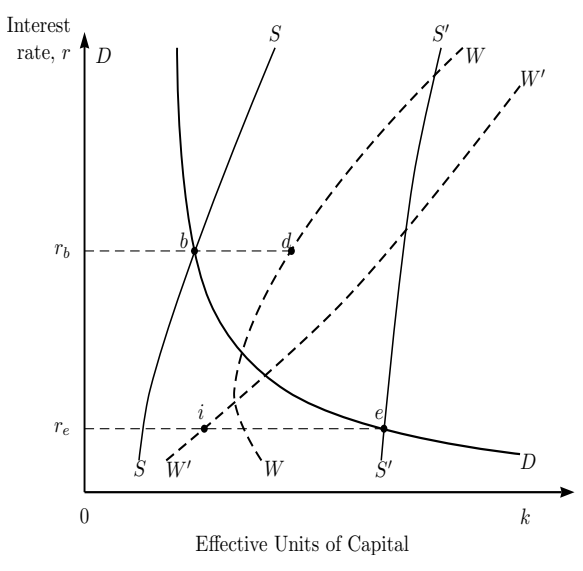

(b) Transfers changes

Figure 1: Aggregate Demand for Real and Total Wealth (with borrowing constraints and selfish individuals). 
In equilibrium, transfer wealth is given by the segments $a c(T<0)$ and $b d(T>0)$, respectively. Transfer wealth has opposite signs in each equilibrium, because in economies where fertility is high (such as point $a$ ), the highest cost is usually associated with childrearing, which leads adults to give more than they receive through their remaining lifetime. In contrast, in economies with both low mortality and low fertility, like point $b$, childrearing costs are overtaken by transfers received when retired. Hence, adults become (net) receivers of transfers.

In Panel 1(b), in contrast, we illustrate a population (post-demographic transition) with two different pension systems. The first case corresponds to an economy with generous pension benefits, with an equilibrium that is depicted by point $b$. A second case is represented by the equilibrium $e$, in which there are no pension benefits. As in Panel 1(a), transfer wealth has opposite signs in each equilibrium. This is because the reduction of pension benefits increases personal savings (Feldstein, 1974), assuming the age of retirement remains the same. Therefore, the demand for real wealth is shifted to the right from curve $S S$ to curve $S^{\prime} S^{\prime}$. In the new equilibrium $e$, transfer wealth is negative since transfers from parents to children are maintained and public transfers to retirees are diminished. Thus, individuals become net transfer givers throughout their lifetime, segment ei $(T<0)$.

The illustration in Figure 1 leads us to the main issue addressed in this Section: What is the impact of a transfer change into capital? The sign and the level of a transfer change on capital depend on the difference between the average age of recipients and givers, as well as on the amount transferred. Thus, if additional transfers go from children to parents (for example moving from equilibrium $e$ to $d$ in Panel 1(b)), the demand for real wealth will decrease, because old age consumption will be financed by transfers rather than by savings. Moreover, higher transfers to the elderly will yield a greater crowding-out of capital. On the other hand, if transfers are reduced -for example, from equilibrium $d$ to $e$ - the opposite argument applies. Throughout the demographic transition, however, the effect of transfers on capital will vary according to the leading generation in the economy; i.e., the baby boomer or the baby bust generation. Section 5 will show these effects along the transition.

\section{The model economy}

In this section, we present the model economy used to estimate the demand for total and real wealth in Spain. All the information on the Spanish lifecycle deficit, asset-based reallocation, and public and private transfers is taken from the NTA for Spain for the year 2000. These age profiles provide us with insight into how Spanish households reallocate their earnings across different age groups. In order to estimate the demand for real, total, and 
transfer wealth in any year $t$ we would need the LCD, ABR, TG, and TF by age from year $t$, until all living cohorts in that year have died. However, only estimates for the year 2000 are available. There are two main approaches for tackling this problem. The first is by using 'economic' synthetic cohorts, where NTA age profiles remain unchanged over time (Lee and Mason, 2010b; Patxot et al., 2010; Bixby and Robles, 2008). This methodology provides useful but restrictive information, in the sense that individuals do not change their savings behavior with changes in prices. This drawback is addressed using a general equilibrium OLG model, which is the methodology applied in this paper. A third possibility is to use a partial equilibrium model, or a mixture of the above-mentioned techniques. Although partial equilibrium is not as restrictive as the synthetic cohort technique, changes in aggregate savings do not affect factor prices, which leads to an overestimation of both positive and negative effects.

Our economy is comprised of public and private sectors, which in turn consist of a government, one neoclassical firm, and a finite number of domestic units. The economy is assumed to be closed to foreign capital investments, but not to foreign labor. Each economic unit will be represented by a set of flows, which are summarized in Table 1. See an extended version, including data sources, in Appendix C.

Table 1: Modeled National Transfer Accounts by Flow and Economic Agent

\begin{tabular}{|l|l|l|l|}
\hline & Individual & Government & Firm \\
\hline \hline \multirow{6}{*}{ Inflows } & $\begin{array}{l}\text { Salary } \\
\text { Asset Income } \\
\text { Familial Transfers } \\
\text { Public Consumption } \\
\text { Public Benefits } \\
\text { Bequests }\end{array}$ & $\begin{array}{l}\text { Progressive Income Tax } \\
\text { Indirect Tax } \\
\text { Corporate Tax } \\
\text { Payroll Tax }\end{array}$ & Revenues \\
& $\begin{array}{l}\text { Pax } \\
\text { Outflows }\end{array}$ & \\
& $\begin{array}{l}\text { Consumption } \\
\text { Childrearing } \\
\text { Familial Transfers } \\
\text { Taxes } \\
\text { Saving }\end{array}$ & $\begin{array}{l}\text { Pensions Benefits } \\
\text { Widowhood Benefits } \\
\text { Maternity Benefits } \\
\text { Public Health }\end{array}$ & $\begin{array}{l}\text { Salaries } \\
\text { Asset Income } \\
\text { Corporate Tax } \\
\text { Net Investment }\end{array}$ \\
& Public Education & Public Others & \\
\hline
\end{tabular}

\subsection{The domestic economic unit}

Each domestic unit is assumed to be comprised of one adult and a number of young dependents. The economic unit can, therefore, be thought of as a regular household split into two, in which two adults live with their children. 
For simplicity, we assume that there is no age difference between the spouses, and that both spouses can accumulate assets. ${ }^{12}$ As a consequence, economic resources are allocated equally between both partners.

A new economic unit is assumed to be set up when an individual is 21 years old $\left(T_{w}\right)$, the age at which children become adults and start making decisions in our model. However, when an adult dies, the economic unit vanishes. From that moment onwards, her/his surviving children (orphans) will be borne by a different household with similar characteristics. To compensate for the additional burden, the new household receives the asset holdings from the adult.

We assume that there is no annuity market, and that our individuals do not save with a bequest motive in mind. Thus, individuals may leave an accidental bequests at death (Yaari, 1965, Case A). In line with SanchezRomero (2009), we assume that adults make decisions for their own wellbeing, as well as for the well-being of their children; i.e., that the utility of raising children is proportional to their consumption. We also assume that all household heads have identical additive instantaneous preferences, which are described at age $x \in\left\{T_{w}, \ldots, \Omega-1\right\}$ by the following Bellman equation: 13

$$
V_{t, x}\left(a_{t, x}\right)=\max _{c_{t, x}}\left\{\lambda_{t, x} \frac{c_{t, x}^{1-\sigma}}{1-\sigma}+\beta p_{t, x} V_{t+1, x+1}\left(a_{t+1, x+1}\right)\right\},
$$

where $\Omega$ is the maximum longevity, $\sigma$ is the constant-relative-risk-aversion

\footnotetext{
${ }^{12}$ Although we assume here that there are no inter-spouse transfers, the NTA database includes this information.

${ }^{13}$ An alternative approach could be to maximize the expected utility of the average consumer in the household (Tobin, 1967; Deaton and Muellbauer, 1980; Ríos-Rull, 2001). By doing so, this expected utility function implies that consumption smoothing takes place at the household level, rather than at the individual level. To illustrate this point, let us assume the following standard household problem without transfers,

$$
V_{x}\left(a_{x}\right)=\max _{c_{x}}\left\{u\left(c_{x} / \lambda_{x}\right)+\beta V_{x+1}\left(a_{x+1}\right)\right\}
$$$$
\text { s.t. } a_{x+1}=(1+r) a_{x}+y_{l_{x}}-c_{x} \text {, for } x \in\left\{T_{w}, \ldots, \Omega-1\right\} \text {, }
$$

where $c_{x}$ is now the total household consumption with a household head of age $x$.

Assuming a logarithmic instantaneous utility function and substituting the flow budget constraint into the Bellman equation

$$
V_{x}\left(a_{x}\right)=\max _{a_{x+1}}\left\{\log \left(\frac{(1+r) a_{x}-a_{x+1}+y_{l}}{\lambda_{x}}\right)+\beta V_{x+1}\left(a_{x+1}\right)\right\} .
$$

Differentiating with respect to $a_{x+1}$ and using the envelope theorem gives the Euler equation

$$
c_{x+1}=c_{x} \beta(1+r) .
$$

Equation (21) implies that household saving does not change over the lifespan for a constant household labor income stream, even when the number of equivalent adult consumers in the household increases. However, a cross-country comparison of consumption profiles using NTA data suggests that households do not smooth their consumption when are childrearing costs.
} 
coefficient, $\beta \in(0,1]$ is the subjective discount factor, $p_{t, x}$ is the probability of surviving from age $x$ to age $x+1$ in year $t, \lambda_{t, x}$ is the number of equivalent adult consumers within an economic unit whose head is $x$ years old, and $c_{t, x}$ is the consumption of private goods and services of the head of the economic unit.

Individuals receive income from three sources. First, the firm compensates its labor force in the form of salaries and pays interest on their assets. The labor force is supplied inelastically only from age $21\left(T_{w}\right)$ to age $63\left(T_{r}\right)$. The salary by age $y_{l t, x}$ is a function of the marginal product of the effective labor $\omega_{t}$, the technological progress $A_{t}$, the effective labor units supplied $\epsilon_{x}$, and the probability of being employed at that age $1-u_{t, x}$. Second, they receive inter-vivos transfers from their parents $\left(\phi_{t, x}^{+}\right)$and accidental bequests $\left(h_{t, x}\right)$ when their parents die. Third, the government provides pension benefits $\left(b_{t, x}\right)$ if they have a child, become a widow/er, or are retired. All pension benefits are assumed to be funded through a PAYG system $\left(\tau_{t}^{s s} y_{l t, x}\right)$.

In order to finance public consumption (health, education, and other public expenditures), the government levies taxes on the following market transfers: consumption of private goods and services $\left(\tau_{t}^{p} \lambda_{t, x} c_{t, x}\right)$, personal income $\left(\tau_{t, x}^{i}\left[r_{t, x}^{i}\left(a_{t, x}+h_{t, x}\right)+\sum_{j \in \mathbb{B}} b_{t, x}^{j}+\left(1-\tau_{t}^{s s}\right) y_{l t, x}\right]\right)$, where $\mathbb{B}$ is the set of all public benefits, and corporate profits. Let denote the consumption of public goods and services at age $x$ in year $t$ by $g_{t, x}$. The disposable income is then used to pay the consumption of the economic unit $\left(\lambda_{t, x} c_{t, x}\right)$, to transfer income to their adult offspring $\left(\phi_{t, x}^{-}\right)$, and to save $\left(a_{t+1, x+1}-a_{t, x}\right) .{ }^{14}$ Therefore, the flow budget constraint of an adult at age $x$ in year $t$ is given by

$$
\begin{aligned}
\left(1+\tau_{t}^{p}\right) \lambda_{t, x} c_{t, x}+\phi_{t, x}^{-}+ & \left.a_{t+1, x+1}=\left(1+r_{t}\left(1-\tau_{t, x}^{i}\right)\right)\left(a_{t, x}+h_{t, x}\right)\right) \\
& +\left(1-\tau_{t, x}^{i}\right)\left[\left(1-\tau_{t}^{s s}\right) y_{l t, x}+\sum_{j \in \mathbb{B}} b_{t, x}^{j}\right]+\phi_{t, x}^{+},
\end{aligned}
$$

where $r_{t}$ is the after-corporate tax (real) interest rate. Although (23) is better for solving the decision problem, in our case it is more convenient to calculate the inter-temporal budget constraint, as in NTA. To do so, we first have to discount the flow budget constraints as if an actuarial note had been purchased; and, second, we have to add all transfers except for those that are directly paid by the firm to the government, such as corporate tax.

\footnotetext{
${ }^{14}$ For the sake of space the specific formula applied to each transfer has been placed in Appendix A
} 
Thus,

$$
\begin{array}{r}
\sum_{s=x}^{\Omega-1}\left\{\prod_{z=x}^{s} \frac{p_{t+z-x, z}}{1+r_{t+z-x}}\right\}\left(g_{t+s-x, s}+c_{t+s-x, s}-y_{l t+s-x, s}\right) \\
=a_{t, x}+\sum_{s=x}^{\Omega-1}\left\{\prod_{z=x}^{s} \frac{p_{t+z-x, z}}{1+r_{t+z-x}}\right\} \eta_{t+s-x, s}
\end{array}
$$

where $\eta_{t, x}$ is total (net) non-market transfers at age $x$ in year $t$. Note that, in Equation (24), the first term on the left-hand-side corresponds to the demand for life cycle wealth by the individual and the second term on the right-hand-side to transfer wealth by the individual. If we denote the actuarial value of stock of human wealth at age $x$ in year $t$ by $\tilde{H}_{t, x}$ and the individual transfer wealth at age $x$ in year $t$ by $t_{t, x}$, then we can rewrite Equation (24) as follows

$$
\sum_{s=x}^{\Omega-1}\left\{\prod_{z=x}^{s} \frac{p_{t+z-x, z}}{1+r_{t+z-x}}\right\}\left(g_{t+s-x, s}+c_{t+s-x, s}\right)-\tilde{H}_{t, x}=a_{t, x}+t_{t, x} .
$$

The optimal consumption of an adult will be given by the usual decision problem. Thus, it can be shown that the first order condition of maximizing (22) subject to (23) and the boundary conditions $a_{t, T_{w}}=0, a_{t, x} \geq 0$, for any $t$, is given by

$$
\frac{c_{t+1, x+1}^{\sigma}}{c_{t, x}^{\sigma}} \geq \frac{1+\tau_{t}^{p}}{1+\tau_{t+1}^{p}} \beta p_{t+1, x+1}\left(1+r_{t+1}\left(1-\tau_{t+1, x+1}^{i}\right)\right),
$$

with equality iff $a_{t, x}>0$.

It is noteworthy that, for a given set of future interest rates, salaries, and demographic characteristics, we can see how consumption at age $T_{w}$ depends on the transfer system established by substituting (26) into (25). Thus, an individual who has negative transfer wealth $\left(t_{t, x}<0\right)$ would, all other things being equal, consume less over her or his lifespan, which implies a lower demand for life cycle wealth. The opposite is also true with a positive transfer wealth $\left(t_{t, x}>0\right)$.

\subsection{The firm}

We model a neoclassical firm using a Cobb-Douglas production function $F\left(K_{t}, A_{t} L_{t}\right)=K_{t}^{\alpha}\left(A_{t} L_{t}\right)^{1-\alpha}$, where $\alpha$ is the capital share; $K$ is the capital stock, which under a closed economy is

$$
K_{t}=\sum_{x=T_{w}}^{\Omega} a_{t, x} N_{t, x}
$$


$A$ is the labor-augmenting technological progress; and $L$ is the total units of labor

$$
L_{t}=\sum_{x=T_{w}}^{T_{r}-1} \epsilon_{x}\left(1-u_{t, x}\right) N_{t+1, x+1} .
$$

Following Hassett and Hubbard (2002), after paying corporate taxes, the net cash flow of the firm (without investment tax credit) is given by

$$
X_{t}=\left(1-\tau_{t}^{c}\right)\left(F\left(K_{t}, A_{t} L_{t}\right)-\omega_{t} A_{t} L_{t}\right)-I_{t},
$$

where $\tau_{t}^{c}$ is the corporate tax rate and $I_{t}$ is gross investment.

The firm chooses $K, L$, and $I$ so as to maximize its individual value $J_{t}=\sum_{s=t}^{\infty} X_{s} \prod_{z=t}^{s} \frac{1}{1+r_{z}}$.

The optimality conditions are given by

$$
\begin{aligned}
\omega_{t} A_{t} & =F_{L}\left(K_{t}, A_{t} L_{t}\right) \\
r_{t}+\delta & =F_{K}\left(K_{t}, A_{t} L_{t}\right) \cdot\left(1-\tau_{t}^{c}\right) \\
I_{t} & =K_{t+1}-K_{t}(1-\delta)
\end{aligned}
$$

where $\delta$ is the capital depreciation rate.

\subsection{Government}

We model a government that has two separate balanced budgets. On the one side, given that the Spanish Social Security administration runs a quasi defined benefit unfunded pension system, we assume that the payroll tax is chosen so as to balance the budget of the pension system,

$$
\sum_{x=T_{w}}^{\Omega-1} \sum_{j \in \mathbb{B}} b_{t, x}^{j} N_{t+1, x+1}=\tau_{t}^{s s} \sum_{x=T_{w}}^{T_{r}-1} y_{l t, x} N_{t+1, x+1} .
$$

On the other side, the government provides public goods and services such as health, education, and others that are financed through personal income taxes, corporate taxes, and taxes on consumption,

$$
\begin{aligned}
& \sum_{x=0}^{\Omega-1} \sum_{j \in \mathbb{J}} g_{t, x}^{j} N_{t+1, x+1}=\tau_{t}^{p} \sum_{x=0}^{\Omega-1} \lambda_{t, x} c_{t, x} N_{t+1, x+1}+\tau_{t}^{c} \frac{r_{t}+\delta}{1-\tau_{t}^{c}} K_{t} \\
& \quad+\sum_{x=T_{w}}^{\Omega-1} \tau_{t, x}^{i}\left(\left(1-\tau_{t}^{s s}\right) y_{l t, x}+\sum_{j \in \mathbb{B}} b_{t, x}^{j}+r_{t}\left(a_{t, x}+h_{t, x}\right)\right) N_{t+1, x+1}
\end{aligned}
$$

where $\mathbb{J}$ is the set of public forms consumption.

All tax rates are assumed to be flat, except for the personal income tax rate, which is progressive. This allow us to better measure transfers of 
wealth and savings, since both variables are age-dependent. Unfortunately, by modeling a progressive personal income tax profile with non-risky assets, we cannot introduce public debt; otherwise, we could not satisfy the nonarbitrage on assets condition. ${ }^{15}$

Finally, to guarantee that Equation (33) is balanced at all times, we assume that any change in aggregate public consumption that is not covered by personal income taxes and corporate income taxes will be financed through indirect taxes.

\subsection{Equilibrium}

Let $x \in \mathcal{X}$ and $t \in \mathcal{T}$. In this economy a Competitive Equilibrium with Transfers is a list of sequences of quantities $c_{t, x}, a_{t, x}, N_{t, x}, A_{t}, L_{t}, K_{t}$, prices $\omega_{t}, r_{t}$, taxes $\tau_{t}^{p}, \tau_{s s}^{p}, \tau_{c}^{p}, \tau_{t, x}^{i}$, public benefits $\left\{b_{t, x}^{j}\right\}_{j \in \mathbb{B}}$, public consumptions $\left\{g_{t, x}^{j}\right\}_{j \in \mathbb{J}}$, and private transfers $h_{t, x}, \phi_{t, x}^{-}, \phi_{t, x}^{+},\left(\lambda_{t, x}-1\right) c_{t, x}$ such that, at each point in time $t$ :

(i) the firm maximizes its value $J_{t}$ by choosing $K_{t}, L_{t}$, and $I_{t}$ according to (29)-(31),

(ii) individuals maximize their expected lifetime utility (22) subject to (23),

(iii) both government budget constraints (32) and (33) are satisfied,

(iv) both capital and labor market clearing conditions (27) and (28) hold,

(v) total private transfers given equal total private transfers received,

(vi) and the good market clearing condition is satisfied,

$$
\begin{aligned}
& F\left(K_{t}, A_{t} L_{t}\right)+K_{t}(1-\delta) \\
& \quad=K_{t+1}+\sum_{x=0}^{\Omega-1} \sum_{j \in \mathbb{J}} g_{t, x}^{j} N_{t+1, x+1}+\sum_{x=T_{w}}^{\Omega-1} \lambda_{t, x} c_{t, x} N_{t+1, x+1} .
\end{aligned}
$$

Note this last condition is equivalent to (9). Moreover, the total consumption in the economy, including children's consumption, is taken into account in the last term of the right-hand-side of the Equation.

\footnotetext{
${ }^{15}$ Although the increase in public debt with respect to GDP in 2009 is expected to have an important impact in the short and medium run in interest rates, in the long run it is likely that a misleading progressive income tax will have a stronger effect on the accumulation of capital.
} 


\section{The estimation of the Spanish demand for wealth}

Figure 2 illustrates with blue circles the LCD of Spain in 2000. This implies that 21.5 million people (53.5\% of the Spanish population) consumed more than they produced in 2000. In the year 2000, the Spanish life cycle deficit is positive for the working ages 26 to 58. Nevertheless, the degree of economic dependency varies with age. As previously mentioned, children are, economically speaking, the most dependent, since they neither work nor accumulate assets to finance their consumption. Their consumption needs are entirely supported by public transfers $(38.2 \%)$ and familial transfers $(61.8 \%)$. By contrast, the cost of supporting people from age 59 and over is lessened because they accumulate wealth before retirement. Indeed, in Spain retirees at age 65 finance $54 \%$ of their LCD with assets.

The Spanish life cycle deficit by age has been calibrated by targeting the NTA age profiles, the main Spanish macroeconomic statistics, and the Spanish government budget in the year 2000. Figure 2 shows the differences between our simulated NTA profiles (solid-colored lines) and the actual NTA data (colored circles) in 2000. The discrepancies between the theoretical and actual NTA profiles can be attributed to the model assumptions. In our simulations, the sharp increases and decreases at ages 21 and 63 are due to the assumption that individuals leave their parental home when they are 21 years old, and retire at age 63. In Spain, the median age at leaving the parental home was 25.7 years for men and 22.9 years for women in the early 1990s (Aassve et al., 2002). Provided that in our model both the individual decision making and demographic characteristics are consistent, parental emancipation around age 25 would lead to an excess in fertility between ages 25-49 and, as a consequence, a burden 15 years later that would unrealistically reduce savings for these age groups. On the other hand, although a mandatory age of retirement is an unrealistic assumption, the aim of the paper is not to estimate how the optimal age of retirement evolves with changes in demography and economic incentives, but to understand the demand for wealth. ${ }^{16}$ Thus, in order to keep the model as simple as possible, we have opted for assuming a constant age of retirement close to the official mean age of retirement in Spain in year 2000.

Another discrepancy between the NTA profiles and our simulation results is that our LCD profile is slightly higher for ages 63 and over. There are several reasons that may explain the difference. Among others, our endogenously determined (real) interest rate is high relative to actual data (around 1\% higher), and thus the slope of our consumption profile for the

\footnotetext{
${ }^{16}$ This is a very interesting question that has been previously modeled for the Spanish case by Jimenez-Martin and Sanchez-Martin (2007) to analyze the effect that minimum pension benefits has on the optimal age of retirement or by Díaz-Giménez and DíazSaavedra (2009) to study how a change in the mandatory age of retirement affect the sustainability of the Spanish pension system.
} 
elderly is steeper than what the NTA LCD profile shows. However, the sensitivity analysis test shows that the Euler equation is robust to changes in both the risk aversion coefficient and the subjective discount factor and, thereby, a different value in either variable cannot explain the discrepancy. Unlike Gan et al. (2005), an alternative explanation is that elderly people do not forecast accurately the remaining number-years lived. Indeed, we are assuming that all the remaining-years lived are healthy years, which could tilt the consumption at old ages up.

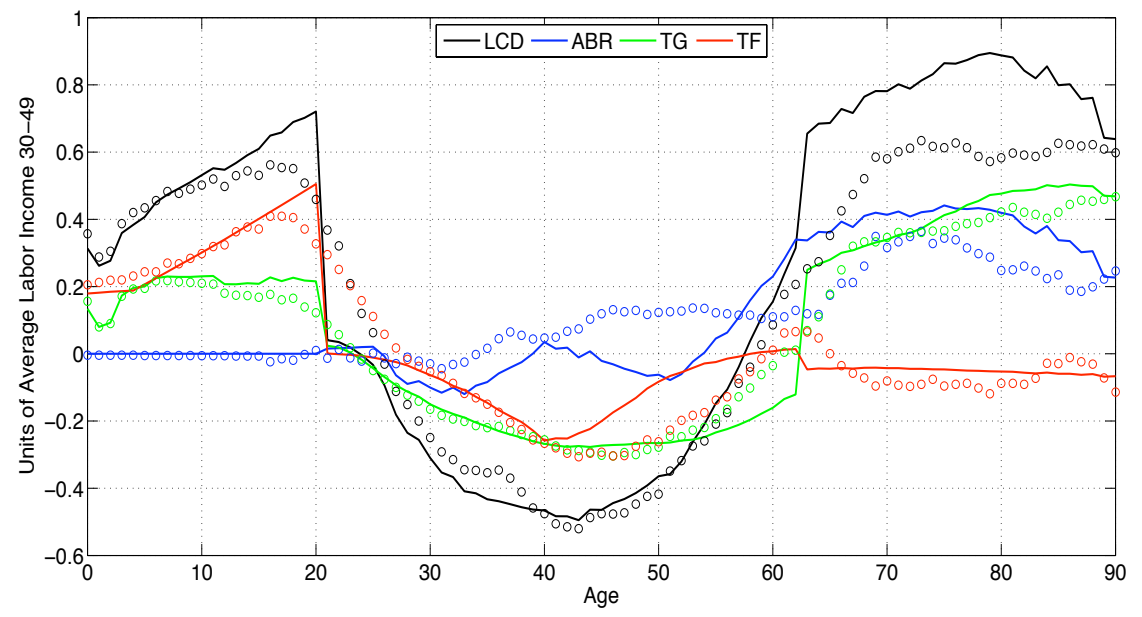

Figure 2: Actual (o) and Simulated (-) Life Cycle Deficit: Spain, year 2000.

There are some features of the Spanish NTA that need to be highlighted. First, ABR is close to zero up to age 40, and it only counts for $15 \%$ of the average gross labor income from ages 30 to 49 (18,410 euros) until retirement. Based on the life cycle theory of saving, this profile suggests that there are important inter-vivos transfers that most likely flow from adult parents to adult children due to cohabitation and housing subsidies. Second, the positive ABR from age 40 until retirement occurs because, in 2000, the cost of childrearing peaks from age 35 to age 50 at the expense of savings. Moreover, the presence of sizable public transfers for retirement might also reinforce this effect. Third, the familial transfer profile is positive for children and negative for adults. Hence parents are (net) transfer givers to their offspring through their lifetimes. A cross-country comparison shows that this is a generalized behavior, except in countries such as Taiwan, South Korea, and Thailand, where adults ages 65 and over are (net) recipients of familial transfers (Lee and Mason, 2010b). In contrast, individuals receive public transfers when they are younger than age 20 or older than age 62 .

In 2000 , the favorable demographic situation makes it easy to support 
the welfare state, as less than $30 \%$ of the average gross labor income from 30-to-49 year-olds is needed to maintain the current public transfer system. ${ }^{17}$ Unfortunately, assuming the current public benefits formulae remain in force, the simulation results show that the working age population will have to spend around $20 \%$ more of their gross salary to support the welfare state system in 2050 (see Figure 3 below). Specifically, the payroll tax increases from $13 \%$ in 2000 to $33.5 \%$ in 2050 (or equivalently social benefits represent $7.76 \%$ of GDP in 2000 and about $20 \%$ of GDP in 2050) and the production tax rate goes from $11.46 \%$ in 2000 to $17 \%$ in 2050 .

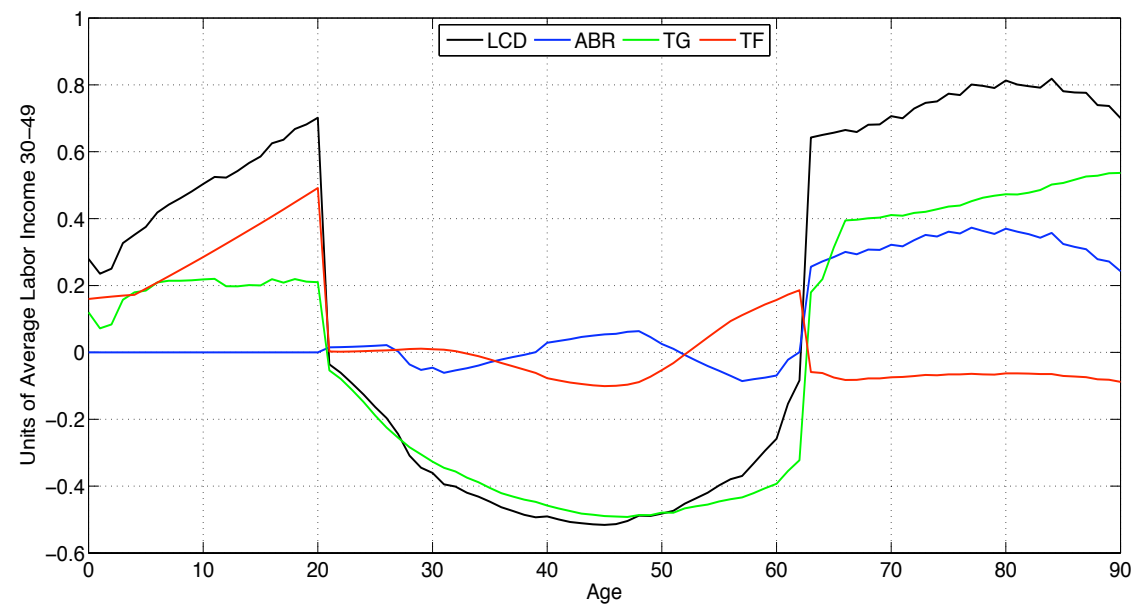

Figure 3: Simulated Life Cycle Deficit: Spain, year 2050.

An increase in the cost of the welfare state in 2050 is not the only change in the LCD. The change in TF is just as dramatic as the change in public transfers, as Figure 3 illustrates. Surprisingly, in 2050, TF is positive for the working age population, except for ages 40 to 52 . A closer look at familial transfers over time (Figure 4) shows that aggregate inter-familial transfer wealth and aggregate bequests turn positive from 2010 to 2100, even when they are modeled as downward transfers. To understand this picture, we need to look at the demographic characteristics of the Spanish population. People born during the baby bust receive more transfers from their older family members than they will actually give to their adult offspring; this is especially true among people who were born in the early 1990s, when the TFR bottomed out. The opposite is also true for the baby boomers. This economic effect is similar to the one described by Easterlin (1980), in

\footnotetext{
${ }^{17}$ In fact the total dependency ratio in Spain from the year 2000 to the year 2010 was the lowest of the last century.
} 
comparison of the economic fortunes of small cohorts relative to those of big cohorts. We can see how the small cohort born in the early 1990s raise interfamilial transfer wealth when they enter the labor market, and up to the moment when they retire, which is precisely the point at which interfamilial transfers start to decline. On the other hand, intra-family transfers do not substantially change over time (i.e., childrearing costs). Thus, by aggregating all the components of the familial transfer of wealth, we find that the aggregate transfer of wealth is always negative, but close to zero from 2050 to 2080 (see Figure 5).

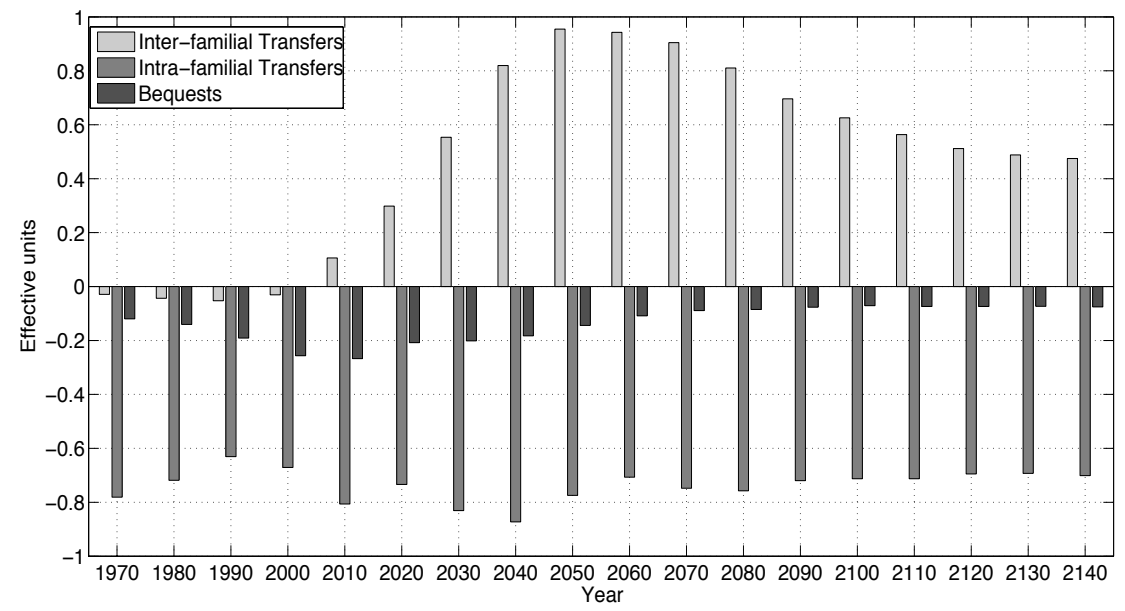

Figure 4: Simulated Aggregate Familial Transfer Wealth: Spain, 1970-2140.

The result of combining aggregate public and familial transfer wealth gives a positive transfer wealth for the 21st century, illustrated by the circled solid line in Figure 5. Consequently, individuals will demand more wealth than the existing stock of capital. We know that, up to a certain threshold, if the population is declining, individuals' demands for life cycle wealth could exceed the existing stock of capital without depleting it. However, based on Eurostat projections of annual migrant flows, we have to rule out this possibility because our projected Spanish population continues to increase (in effective units) up to 2020 (see Figure 9 in the Appendix). As a consequence, the second demographic dividend will not be permanent (Mason and Lee, 2006), since transfers to the elderly are quite generous and private transfer wealth is positive. In short, the additional accumulation of assets because of an extended retirement period (longer life expectancy after retirement) will not lead to a permanent increase in the capital-to-output ratio. Our simulations suggest that the capital-to-output ratio will reach the value of 3 in the 2040s and will progressively decline to a steady level of 
about 2.65 .

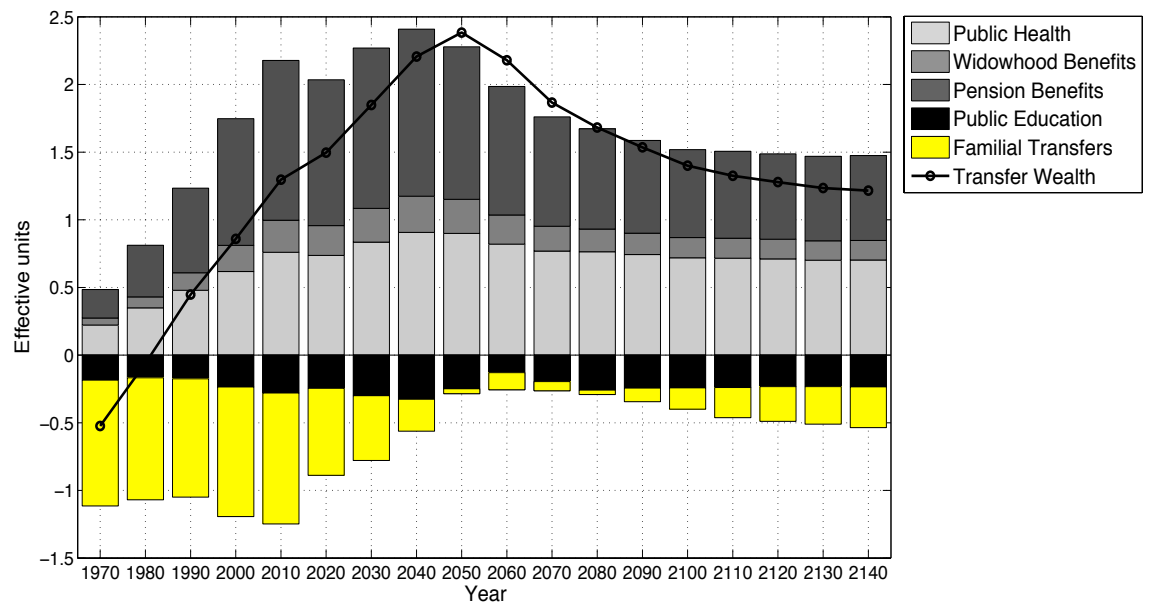

Figure 5: Simulated Aggregate Transfer Wealth: Spain, 1970-2140.

Figure 6 shows the evolution of the capital market, including the demand for life cycle wealth. The equilibrium interest rate is represented in the vertical axe, while the units of effective capital are on the horizontal axe. The black solid line corresponds to the supply of capital in equilibrium, or demand for real wealth, from 1980 to 2140 (when the final steady-state is reached). The blue solid line is the associated demand for life cycle wealth over time, or the wealth demanded by individuals to satisfy their remaining lifetime consumption. Taking this into account, for any given year, if the demand for life cycle wealth exceeds the supply of capital, the population expect to consume more during their remaining lifetime than the existing stock of capital allows them to. This is because they expect to be net receivers of transfers throughout their lifespan (Lee, 1994).

Even though the demand for life cycle wealth exceeds the stock of capital, the entry of the babyboomers into retirement, who have more capital accumulated than previous cohorts, will boost the capital stock per worker up to 2040. The after-tax (real) interest rate will be close to $5 \%$ in 2040, and the productivity of labor will increase at a rate of $1.60 \%$ per year from 2010 


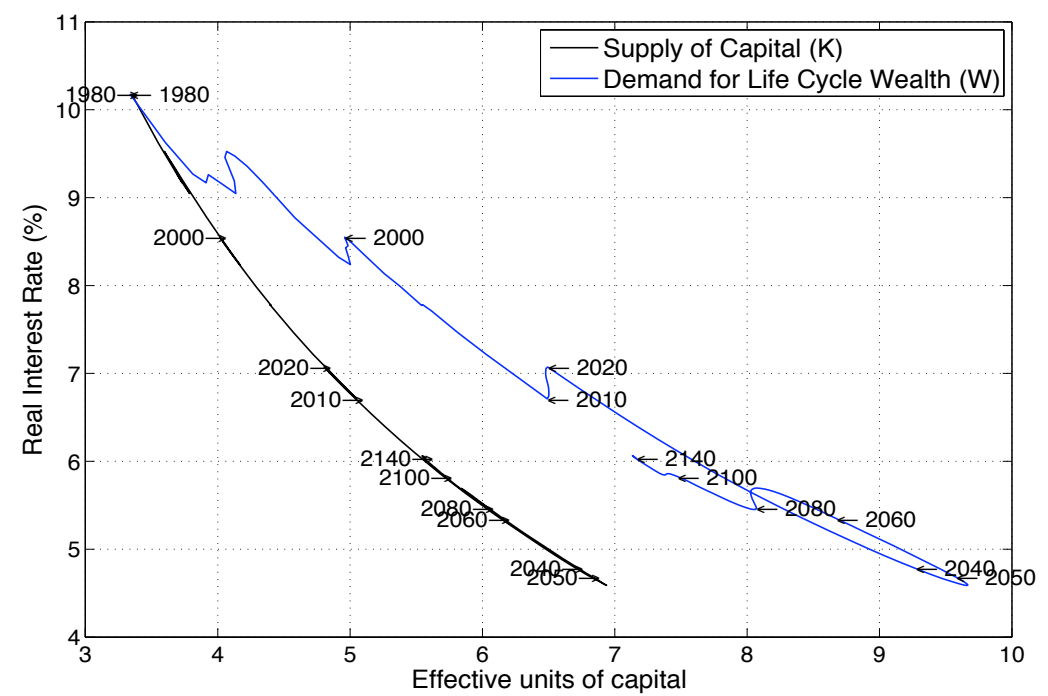

Figure 6: Equilibrium Interest Rate and Demand for Wealth (Life Cycle and Real): Spain, 1980-2140.

to $2040 .{ }^{18}$ Simultaneously, payroll taxes will rise at a rate of $2.17 \%$ per year during the same period, offsetting the gain in labor productivity. Hence, by maintaining the current Social Security system, disposable income will decrease by $17.1 \%(0.57 \% \times 30$ years $)$ from 2010 to 2040 . It is noteworthy the effect that the current crisis has on the demand for real and life cycle wealth from year 2010 to $2020 .{ }^{19}$ According to Figure 6 the stock of capital decreases whereas the demand for life cycle wealth remains unchanged. This is because the generation who were born in the 1990s, with positive total transfers wealth, do not accumulate savings at the same rate as the growth rate of employment. Hence, the simulation suggests that the Spanish economy will need more than a decade to have the same stock per effective labor

\footnotetext{
${ }^{18}$ Holding the technology constant and assuming a Cobb-Douglas production function, the increase in labor productivity was calculated according to the formula:

$$
\log \frac{\omega_{t+T}}{\omega_{t}}=\log \frac{A_{t+T}}{A_{t}}+\alpha \log \frac{k_{t+T}}{k_{t}} .
$$

Assuming that at time $t+T$ any variable $X_{t+T}$ can be expressed according to an initial value $X_{t}$ times a constant growth rate $g_{X}$ during $T$ periods, then we find that the growth rate of salaries $g_{w}$ is equal to $g_{A}+\alpha g_{k} \approx 1.26 \%+0.36 \cdot 0.95 \%$, where the set $\left\{g_{A}, g_{k}\right\}$ correspond to the growth rate of the labor-augmenting technological progress and the growth rate of effective units of capital, respectively.

${ }^{19}$ We have assumed that the observed employment rates by age in 2010 linearly improve to the values projected by the European Policy Committee in 2019.
} 
than before the crisis.

How will the decrease in disposable income affect the stock of capital? On the one hand, the stock of effective capital will fall because of the decrease in disposable income, and the accompanying decline in the savings rate. On the other, the stock of effective capital will rise because of the decrease in the population, assuming the rest of the variables remain the same (Lau, 2009; d'Albis, 2007). According to our simulations, the decrease in disposable income has a greater impact than the negative population growth rate and the longer life expectancy. However the disposable income effect does not fully explain the stock of capital in the new steady state. Most likely, the baby boom - baby bust (demographic effect), coupled with a generous welfare system (economic effect), explain the path to the new steady state. The aging of the population opens a second window of opportunity by increasing the capital-to-labor ratio when baby boomers exit to retirement (Mason and Lee, 2006). This demographic effect counts for the increase of the effective capital from 2010 to 2040 . The baby bust generation will save less than the baby boomers. First, the baby bust generation expect to be net receivers of inter-familial transfers, which increases consumption (see Figure 4). Second, the increasing number of retirees raises the cost of financing the welfare state, which reduces the disposable income of the baby bust generation. The combination of both effects will progressively reduce the productivity of labor until the new equilibrium is reached.

In the new steady state, the demands for real and life cycle wealth are higher than those in 2000 (see Figure 6). Assuming technology will not change, the increase in the capital-to-labor ratio will lead to a $2 \%$ decrease in the real interest rate, and a subsequent increase in labor productivity. Consequently, aggregate consumption will be greater in the final steady state than in 2000. The downside of Figure 6 is the progressive movement to the left of the demand for life cycle wealth from 2050 up to the final steady state. This means that, from 2050 onwards, the standard of living (in effective units) of future generations will progressively decline; even though, in aggregate terms, people in 2050 will be better off than those in 2000 .

\section{Conclusion}

In this paper, we have studied the evolution of the stock of capital in Spain. To that purpose, we have implemented a general equilibrium OLG model that includes realistic public and familial transfers by age. The size and direction of the observed Spanish intergenerational transfers draw upon the National Transfer Accounts database (NTA), a new international database that makes available estimates of marketable and non-marketable interage flows that are consistent with National Income and Product Accounts (NIPA). 
Provided the set of transfers by age in 2000 is maintained in the future, the simulation results show a decrease in disposable income of $17 \%$ from 2010 to 2040, due to population aging. Nevertheless, asset holdings and consumption, both in per capita terms, experience a temporary and considerable increase. We show how the rapid increase in both variables is due to the pronounced baby boom and baby bust in Spain. First, effective capital increases because the population at working ages decreases (even with migration), and because workers have access to a greater stock of productive capital. This is known as the second demographic dividend (Mason and Lee, 2006). Second, consumption per capita rises because of the increase in transfer wealth. Thus, on the one hand, baby boomers benefit from the current Social Security system, receiving substantial benefits relative to their contributions. As a result, baby boomers exchange part of their savings for consumption. On the other hand, the baby bust generation are depleting their capital because they have received a large quantity of inter-vivos transfers from their parents (babyboomers), relative to the amounts they will leave to their children.

In sum, the effects of the Spanish baby boom and baby bust coupled with the generous pension benefits, will lead to a progressive decline in the standard of living for those alive after 2040. Thus, salaries and effective capital will decrease, yielding lower aggregate consumption, higher interest rates, and consequently a temporary second demographic dividend.

Further research is needed in order to explore the extent to which the results depend on the underlying model assumptions and the extent to which the 2000 or future NTA estimates can be used to modify it. This paper has taken the simplest possible approach as a starting point. Future research could consider other saving motives and other forms of altruism that could lead to more flexible or endogenous transfers. Similarly considering endogenous fertility and productivity growth would be other examples worth to analyze.

\section{References}

Aassve, A., F. C. Billari, S. Mazzuco, and F. Ongaro (2002). Leaving Home: a Comparative Analysis of ECHP Data. Journal of European Social Policy 12(4), 259-275.

Auerbach, A. J., J. Gokhale, and L. J. Kotlikoff (1991). Generational Accounts: A Meaningful Alternative to Deficit Accounting. Tax Policy and the Economy 5, 55-110.

Bixby, L. R. and A. Robles (2008, enero-marzo). Los Dividendos Demograficos y la Economa del Ciclo Vital en Costa Rica. Papeles de Poblacion (55), 9-34. 
Bommier, A. and R. D. Lee (2003, February). Overlapping Generations Models with Realistic Demography. Journal of Population Economics 16(1), 135-160.

Cubel, A. and J. Palafox (1997). El Stock de Capital de la Economía Española. 1900-1958. Revista de Historia Industrial 12, 113-146.

d'Albis, H. (2007, January). Demographic Structure and Capital Accumulation. Journal of Economic Theory 132(1), 411-434.

Deaton, A. S. and J. Muellbauer (1980). Economics and Consumer Behaviour. Cambridge University Press.

Diamond, P. A. (1965). National Debt in a Neoclassical Growth Model. The American Economic Review 55(5), 1126-1150.

Diamond, P. A. (1977, December). A Framework for Social Security Analysis. Journal of Public Economics 8(3), 275-298.

Díaz-Giménez, J. and J. Díaz-Saavedra (2009). Delaying Retirement in Spain. Review of Economic Dynamics 12, 147-167.

Easterlin, R. A. (1980). Birth and Fortune: The Impact of Numbers on Personal Welfare. New York: Basic Books.

European Commission (DG ECFIN) and the European Policy Committee (AWG) (2009, April). 2009 Ageing Report: Economic and Budgetary Projections for the EU-27 Member States (2008-2060). Technical Report 2, European Commission.

Feldstein, M. (1974). Social Security, Induced Retirement, and Aggregate Capital Accumulation. Journal of Political Economy 82(5), 905-926.

Gan, L., M. Hurd, and D. McFadden (2005). Analyses in the Economics of Aging, Chapter Individuals Subjective Survival Curves. Number 12 in National Bureau of Economic Research Conference Report. The University of Chicago Press.

Gokhale, J., L. J. Kotlikoff, J. Sabelhaus, B. Bosworth, and R. Haveman (1996). Understanding the Postwar Decline in U.S. Saving: A Cohort Analysis. Brookings Papers on Economic Activity 1996(1), 315-407.

Hassett, K. A. and R. G. Hubbard (2002, June). Tax Policy and Business Investment. In A. J. Auerbach and M. Feldstein (Eds.), Handbook of Public Economics, Volume 3 of Handbook of Public Economics, Chapter 20, pp. 1293-1343. Elsevier Science Publisher B.V. 
Human Mortality Database (2009). University of California, Berkeley (USA), and Max Planck Institute for Demography Research (Germany). available at www.mortality.org (data downloaded in June, 2009).

Jimenez-Martin, S. and A. R. Sanchez-Martin (2007). An Evaluation of the Life Cycle Effects of Minimum Pensions on Retirement Behavior. Journal of Applied Econometrics 22(5), 923-950.

Judd, K. L. (1998). Numerical Methods in Economics. Cambridge, Massachussetts: Massachussetts Institute of Technology.

Kotlikoff, L. and L. Summers (1981, August). The Role of Intergenerational Transfers in Aggregate Capital Accumulation. The Journal of Political Economy 89(2), 706-732.

Lau, S.-H. P. (2009). Demographic Structure and Capital Accumulation: A Quantitative Assesment. Journal of Economic Dynamics and Control 33, $554-567$.

Lee, R. D. (1993, August). Modeling and Forecasting the Time Series of US Fertility: Age Distribution, Range, and Ultimate Level. International Journal of Forecasting 9(2), 187-202.

Lee, R. D. (1994, Autumn). Age Structure, Intergenerational Transfer, and Wealth: A New Approach, with Applications to the United States. The Journal of Human Resources 29(4), 1027-1063.

Lee, R. D. and L. R. Carter (1992, September). Modeling and Forecasting U.S. Mortality. Journal of the American Statistical Association 87(419), 659-671.

Lee, R. D. and A. Mason (Eds.) (2010a). Population Aging and the Generational Economy: A Global Perspective. Edward Elgar, (Forthcoming).

Lee, R. D. and A. Mason (2010b, Forthcoming). Some Macroeconomic Aspects of Global Population Aging. Demography.

Maddison, A. (2006). The World Economy, Volume 1: a Millenial Perspective - Volume 2: Historical Statistics. Paris, OECD: Development Centre Studies.

Mas, M., J. Pérez, and E. Uriel (Eds.) (1995). El Stock de Capital en España y su Ditribución Territorial, Volume 4 vols. Bilbao: Fundación Banco Bilbao-Vizcaya.

Mason, A. and R. D. Lee (2006). Reform and Support Systems for the Elderly in Developing Countries: Capturing the Second Demographic Dividend. GENUS LXII(2), 11-35. 
Nicolau, R. (2005). Estadísticas Históricas de España: siglos XIX-XX (Segunda ed.), Volume I, Chapter Población, Salud y Actividad, pp. 77-154. Plaza de San Nicolás, 4. 48005 Bilbao: Fundación BBVA.

Patxot, C., E. Renteria, M. Sanchez-Romero, and G. Souto (2010). Integrated Results for GA and NTA for Spain: Some Implications for the Sustainability of the Welfare State. Papeles de trabajo, Instituto de Estudios Fiscales, 7/2010 (under evaluation).

Reinhart, C., M. Ogaki, and J. Ostry (1996). Saving Behavior in Lowand Middle-Income Developing Countries: A Comparison. IMF Staff Papers $43(1), 38-71$.

Ríos-Rull, J.-V. (2001, May). Population Changes and Capital Accumulation: The Aging of the Baby Boom. Advances in Macroeconomics 1(1), Article 7.

Rojas, J. A. (2004). On the Interaction between Education and Social Security. Review of Economic Dynamics 7, 932-957.

Rojas, J. A. (2005). Life Cycle Earnings, Cohort Size Effects and Social Security: A Quantitative Exploration. Journal of Public Economics 89, 465-485.

Samuelson, P. A. (1958, December). An Exact Consumption-Loan Model of Interest with or without the Social Contrivance of Money. The Journal of Political Economy 66, 467-482.

Sanchez-Martin, A. R. (2010, January). Endogenous Retirement and Public Pension System Reform in Spain. Economic Modelling 27(1), 336-349.

Sanchez-Romero, M. (2009). Demographic Transition and Rapid Economic Growth: The Case of Taiwan.

Tobin, J. (1967). Ten Economic Studies in the Tradition of Irving Fisher, Chapter Life Cycle Saving and Balanced Growth. John Wiley and Sons.

Willis, R. J. (1988). Economics of Changing Age Distributions in Developed Countries, Chapter A Theory of the Equilibrium Interest Rate in an Overlapping Generations Model: Life Cycles, Institutions, and Population Growth, pp. 106-138. Oxford University Press.

Yaari, M. (1965, April). Uncertain Lifetime, Life Insurance, and the Theory of the Consumer. The Review of the Economic Studies 5(3), 304-317. 


\section{A Calibration}

This section presents the calibration process of tax profiles, social benefits, public expenditures, and inter- and intra-familial transfers using the Spanish NTA database for year 2000. As shown in Table 2 (see numbers in brackets) around $70 \%$ of the Spanish government budget is modeled (or $24.36 \%$ of the GDP), and there are a great number of private transfers, including bequests. The calibration is done in two steps. First, we try to replicate each age profile. Second, public transfers are adjusted to match the Spanish government budget in 2000. Meanwhile, private transfers are adjusted to replicate the life cycle deficit by age.

This section is organized as follows. First, the three variables exogenous to our model are introduced: Spanish demography, age-specific labor productivity indexes, and the labor-augmenting technological progress. A detailed explanation of the source of information and the estimation process is given. Second, we proceed with the calibration of the endogenous variables. Specifically, we present the formulae used to model public and private consumption expenditures, taxes profiles, public pension benefits, and private transfers.

Table 2: UN SNA Classified Tax Revenues and Public Expenditures by Function in 2000

\begin{tabular}{lrc}
\hline Expenditures & \%GDP & \\
\hline Property income, payable & 3.27 & \\
Social benefits other that in kind & 12.08 & \\
Pensions & 10.18 & \\
Contributory & 9.91 & \\
-Retirement & 6.20 & $(6.30)$ \\
-Disability & 1.73 & \\
-Survivors & 1.87 & $(1.35)$ \\
-Maternity & 0.11 & $(0.10)$ \\
Non contributory & 0.28 & \\
Unemployment & 1.38 & \\
Other social protection & 0.52 & \\
Other current transfers & 1.27 & \\
Government final consumption & 17.35 & \\
Education & 4.39 & $(4.22)$ \\
Health & 5.23 & $(5.23)$ \\
Long-term care & 0.33 & \\
Other (in-kind) & 7.40 & $(6.96)$ \\
Saving, net & 1.46 & \\
\hline Total & 35.43 & $(24.36)$ \\
\hline
\end{tabular}

\begin{tabular}{lrr}
\hline Revenues & \%GDP & \\
\hline Taxes on production and imports & 10.31 & \\
Taxes on production and imports & 11.46 & $(6.22)$ \\
Subsidies & -1.14 & \\
Property income, receivable & 1.12 & \\
Current taxes on income and wealth & 10.25 & \\
Taxes on income & 9.84 & $(10.19)$ \\
Individual income tax & 6.70 & $(6.98)$ \\
Corporate income tax & 3.14 & $(3.21)$ \\
Other current taxes & 0.41 & \\
Social contributions & 12.99 & $(7.76)$ \\
Other current transfers & 0.76 &
\end{tabular}

\section{A.1 The Spanish demography}

In this section, we describe how population data are obtained so that they fit our Large-scale OLG model. In particular, we derive the population by employing a population matrix by age and time, Leslie matrix, abstracting from gender differences. To improve the quality of the computations, both the initial and the final economic situations need to be in a steady state, which implies the need for a stable population. This means that, in addition to the need to project a future population 
Table 3: Gross National Disposable Income, Spain in 2000

\begin{tabular}{lr}
\hline Consumption & 77.54 \\
Government final consumption & 17.35 \\
Private final consumption & 60.19 \\
Net Saving & 8.68 \\
Public saving & 1.46 \\
Private saving & 7.23 \\
Consumption of fixed capital & 13.78 \\
\hline Total & 100.00 \\
\hline
\end{tabular}

\begin{tabular}{lr}
\hline Compensation of employees (CE) & 49.98 \\
Net CE from ROW & -0.02 \\
Operating surplus (OS) & 40.90 \\
Net prop and entrep income from ROW & -1.12 \\
Indirect taxes less subsidies (NIT) & 10.02 \\
NIT from ROW & 0.29 \\
Net current transfers from ROW & -0.05 \\
\hline Total & 100.00 \\
\hline
\end{tabular}

until its final state we also need to obtain an initial steady state. ${ }^{20}$

Data availability imposes some constraints on the estimation process. First, data on historical population are available from the Human Mortality Database (2009) (HMD). This database contains population and mortality rates by age and gender from 1908 to 2006. Nevertheless, even for this period, some adjustments are needed. Some of them simply consist of smoothing some unrealistic peaks. ${ }^{21}$ Second, the most important adjustments deal with the need to project past population backwards from 1908 to the initial steady state. Third, and regarding the future, the assumptions on the main demographic parameters are taken from the National Statistic Institute (INE) and Eurostat. Fourth, fertility data are truncated in order to satisfy the assumption that individuals start making decisions when they set up their own household. Finally, we need to take into account that the model works with representative agents, and does not distinguish by gender, which implies that all parameters will need to be adjusted properly.

The process of obtaining a coherent evolution of past and future Spanish population is as follows. The starting point is recovering the observed population for the period 1908-2006. The second step is fixing the mortality and fertility assumptions in order to derive the direct and inverse population projection matrices. Estimation methods are used to derive age-specific mortality rates (Lee and Carter, 1992) and age-specific fertility rates (Lee, 1993), starting from the data available. Thus, we assumed that fertility is an additive process:

$$
\mathbf{f}(t, x)=\mathbf{a}_{x}^{f}+\sum_{i=1}^{2} \mathbf{f}_{t}^{(i)} \cdot \mathbf{b}_{x}^{f,(i)}+\epsilon_{t, x}^{f}, \text { where } \epsilon_{t, x}^{f} \sim \text { i.i.d. }\left(0, \sigma_{\epsilon^{f}}^{2}\right),
$$

while mortality is a multiplicative process:

$$
\log \mathbf{m}(t, x)=\mathbf{a}_{x}^{m}+\mathbf{k}_{t} \cdot \mathbf{b}_{x}^{m}+\epsilon_{t, x}^{m}, \text { where } \epsilon_{t, x}^{m} \sim \text { i.i.d. }\left(0, \sigma_{\epsilon^{m}}^{2}\right) .
$$

Future age-specific mortality rates are forecasted using the (Lee and Carter, 1992) methodology. In order to reach a stable population, mortality rates are kept constant from 2050 onwards, with a forecasted life expectancy at birth (total) of 86

\footnotetext{
${ }^{20}$ We deviate from many of the available large-scale OLG models for Spain, in that our economy is in steady-state in 1870 rather than in 1960, capturing most of the Spanish demographic transition features (Ríos-Rull, 2001; Díaz-Giménez and Díaz-Saavedra, 2009; Rojas, 2004, 2005).

${ }^{21}$ For the first decades, until year 1960, an unrealistic peak is observed in the last age of the decade. Hence a smoothing procedure is applied using inverse projection matrices.
} 
years, as Figure 7 shows. Mortality rates prior to 1908 are calculated by adjusting the estimated values in Equation (A-2) to historical life expectancies reported in Nicolau (2005). In the case of fertility, and regarding the past, observed age-specific fertility for the period 1971-2007 are used to estimate Equation (A-1) and to predict past fertility, both for the rest of the observable period (1908-1971) and for the projected past. Regarding the future, some additional information is available: the INE projected age-specific fertility rates for the period 2002-2031. Using these rates, a final total fertility rate of 1.53 is reached in 2030 , and remains constant thereafter (see Figure 7).

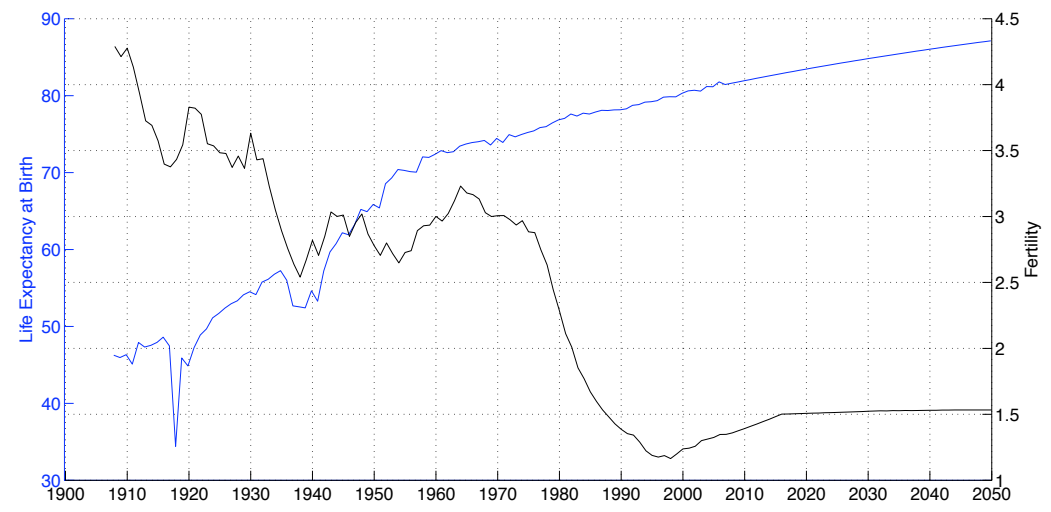

Figure 7: Spain: Life Expectancy at Birth and TFR, 1908-2050

Source: Author's calculations using HMD and Eurostat.

Regarding migration assumptions, we also opt for the Eurostat assumptions. ${ }^{22}$ Table 4 shows the annual flow of net immigrants assumed in the Eurostat population projection. A similar procedure used to derive past mortality rates is used to estimate annual flow of net migrants by age from 2008 onwards (see Figure 8). Hence, in line with Eurostat assumptions, future immigrants (the observed level is taken until year 2008) are assumed to decrease, first sharply until 2020, and later more steadily. In order to have a stable population, we assume that the number of migrants gradually decreases to zero from 2060 onwards (see Table 4). ${ }^{23}$

After collecting and estimating the necessary information, we project the population by single years of age using Leslie matrices (inverse population projection in the case of the past). Figure 9 shows the population size over time for an open

\footnotetext{
${ }^{22}$ The last official projections derived by the National Statistics Institute (INE, 2005) assumed in their baseline a gradual reduction in annual net immigrants, from the current number of more than half million, to a constant value of 260.000 in 2060 . A low immigration hypothesis (tending to 100.000) was derived in order to produce an outcome similar to past European projections (Eurostat 2006). The new Eurostat projection is more realistic in the initial value of immigrants, but still assumes a lower long-term level.

${ }^{23} \mathrm{~A}$ stable population can also be reached if we assume a constant proportion of (net) migrants by age over time. Nonetheless, the total number of migrants would still not match with Eurostat assumptions.
} 
Table 4: Annual net immigrants (Eurostat population projections)

\begin{tabular}{|c|c|c|c|c|c|c|c|c|c|c|c|}
\hline 2008 & 2010 & 2015 & 2020 & 2025 & 2030 & 2035 & 2040 & 2045 & 2050 & 2055 & 2060 \\
\hline 623.4 & 540.2 & 375.8 & 263.1 & 190.4 & 160.8 & 149.3 & 150.5 & 146.1 & 135.2 & 131.8 & 129.9 \\
\hline
\end{tabular}

Source: European Commission (DG ECFIN) and the European Policy Committee (AWG) (2009)
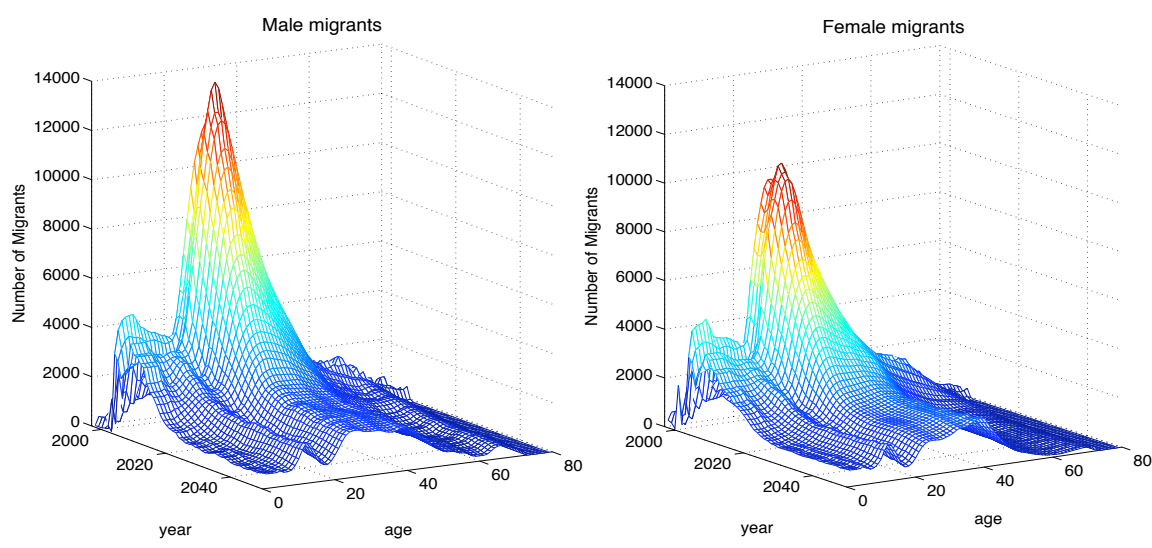

Figure 8: Spain: Estimated Net Migrants by Age and Year, 1997-2050

Source: Author's calculations based on HMD and Eurostat. 
and closed economy to migration since 1975.

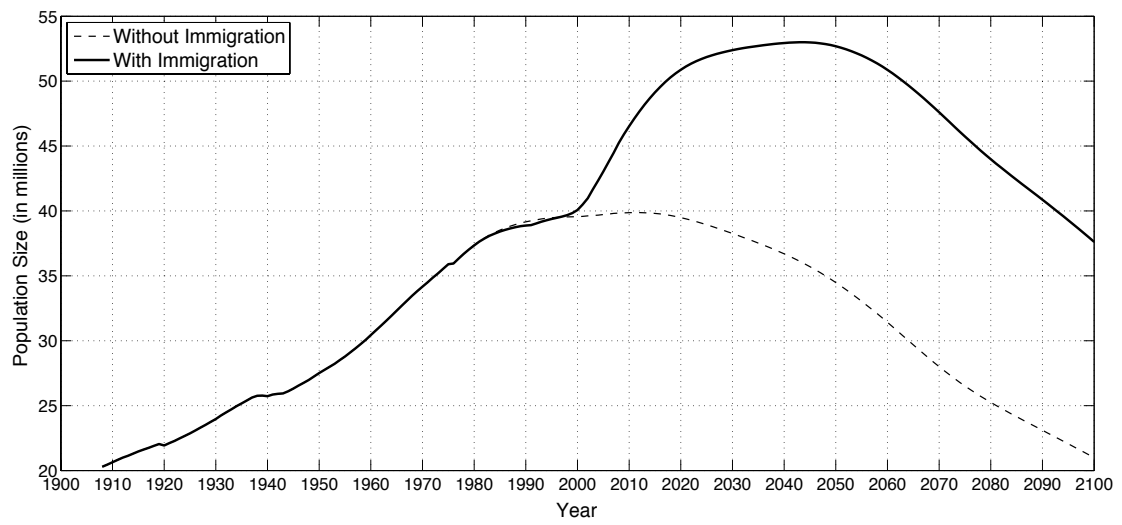

Figure 9: Spain: Historical and Projected Population Size from 1900 to 2100

Source: HMD, Eurostat, and author's calculations.

\section{A.2 Age-specific labor productivity indexes}

We assume that age-specific labor productivity indexes do not change over time. Differences in labor income between generations are driven by two time components (labor-augmenting technological progress and the marginal product of effective labor) as well as by changes in unemployment rates by age and time. Unemployment rates draw from two sources: i) historical unemployment data from 1972 to 2009 are taken from the OECD database and ii) projected data from 2009 to 2060 draw upon the Budgetary projections (baseline scenario 2008) of the European Policy Committee. To introduce the dramatic decline in employment in years 2008-2009 in the analysis, and the expected slow recovery of the crisis, we have substituted the forecasted unemployment rates for a linear interpolation by age of the unemployment rates between year 2009 and year 2019. Age-specific labor productivity indexes are obtained by taking "labor earnings" by age (including self-employment) from Muestra Continua de Vidas Laborales (MCVL) database for the period 1982 to 2006. The statistical method used to compute the age-specific labor productivity indexes is the singular value decomposition. In the following, the database and estimation process is described.

\section{A.2.1 The continuous working life sample (MCVL)}

The MCVL is a sample extracted from Social Security administrative data. ${ }^{24}$ It is comprised of $4 \%$ of all individuals registered with the Social Security administration (both contributors and recipients of benefits) over the sampling year. The dataset

\footnotetext{
${ }^{24}$ See MTAS (2006b) for a detailed description of the Muestra Continua de Vidas Laborales (MCVL), available upon request at

http://www.seg-social.es/Internet_1/Estadistica/Est/index.htm.
} 
includes the entire life histories of the individuals selected that are contained in the Social Security records. ${ }^{25}$ Thus, although it is not a pure panel, the dataset is rich in longitudinal data. However, this feature complicates both the structure of the information and the data selection, since the registration unit varies substantially either by person (in the personal data file), or by contract (in the affiliation file), or by contract and year (in the contribution file). Furthermore, the quality of the data is not homogenous, deteriorating as they go back in time. Specifically, the data collection was initiated at different points in time: data on pensions were first included around 1996, data on contributions were introduced around 1980, while some data on affiliation (contract registering) are available from as early as 1970. Clearly, all these factors condition our analysis.

Among the difficulties that can arise in dealing with such a large administrative dataset (the sample size reaches about a million people in 2005), the most challenging are dealing with empty contribution bases, on the one hand; and relating contribution, affiliation, and benefits data for the same individual, on the other. In particular, in order to extract reliable data regarding contributions in a specific time unit, it is necessary to follow up all the contracts in which an individual has been involved, computing time and contribution separately so as to avoid an erroneous correspondence between working time and contribution per unit of time. Below we describe in detail how we dealt with this.

The annual contribution period, or working time, is obtained by recovering all the contracts signed by the individual for each year, taking into account parttime work, as well as the possibility that contracts may have run simultaneously. At the same time, the average hourly contribution is obtained. One of the main problems we faced was the existence of missing contribution data. This can occur either within a contract registered in the contribution file, or due to a lack of correspondence between the affiliation data (starting long before 1980) and contribution data (starting in 1980). For example, we might find that, even after 1980, there is no recorded contribution for one specific worker, while data regarding affiliation showed the worker to be actually contributing. ${ }^{26}$ An imputation process is developed to provide figures for the missing contributions. By tracking affiliation and contribution data, we treat missing values differently depending upon whether the individual is actually working (actual missing value) or not (if he is out of the labor force). In the former case, data from the same individual are used in order to recover absent contributions. If this is not available in the same year, the contract is discarded. Once this imputation process is terminated, the average hourly wage is obtained for each year and age.

\footnotetext{
${ }^{25}$ Workers, pensioners, and individuals receiving unemployment benefits or benefits prior to early retirement are included. The latter can be identified by the type of relation they have with the Social Security administration.

${ }^{26}$ Information regarding contributions was first gathered in 1980, but it is more reliable after 2001. The providers of the sample found that the share of contracts with missing data fell from $78 \%$ in 1984 to $94 \%$ in 1992 and to $99 \%$ in 2003.
} 


\section{A.2.2 Statistical calculation}

Since the simulated outputs are in real terms, we calculated real labor earnings by age using the IPC from INE. ${ }^{27}$ Then, assuming a multiplicative relation between the time component and the age component, we use the singular value decomposition method to calculate age-specific labor productivity indexes (Sanchez-Romero, 2009).

Proof. Let $\mathbf{Y}=\left[y_{t, x}\right]_{t=1982 \ldots 2006 ; x=T_{w} \ldots T_{r}-1}$ be a matrix $T \times N$ of salaries by age and time. Recall that the real salary is divided into a time component, $\nu_{t}=w_{t} A_{t}$, and an age component, $\epsilon_{x}$, as follows

$$
y_{t, x}=w_{t} A_{t} \epsilon_{x} \Rightarrow y_{t, x}=\nu_{t} \epsilon_{x} .
$$

Let define $\nu=\left[\nu_{1}, \nu_{2}, \ldots, \nu_{T}\right]^{\prime}$ the vector of time components and $\mathbf{e}=\left[\epsilon_{1}, \epsilon_{2}, \ldots, \epsilon_{N}\right]^{\prime}$ the vector of age component. Then, $\mathbf{Y}$ can be rewritten as

$$
\mathbf{Y}=\nu \cdot \mathbf{e}^{\prime}=\left(\begin{array}{cccc}
\nu_{1} \epsilon_{1} & \nu_{1} \epsilon_{2} & \cdots & \nu_{1} \epsilon_{N} \\
\nu_{2} \epsilon_{1} & \nu_{2} \epsilon_{2} & \cdots & \nu_{2} \epsilon_{N} \\
\vdots & \vdots & \ddots & \vdots \\
\nu_{T} \epsilon_{1} & \nu_{T} \epsilon_{2} & \cdots & \nu_{T} \epsilon_{N}
\end{array}\right)
$$

Let the singular value decomposition of the matrix of salaries be

$$
\mathbf{Y}_{T \times N}=\mathbf{U}_{T \times T} \cdot \Lambda_{T \times N} \cdot \mathbf{V}_{N \times N} .
$$

where $\mathbf{U}$ and $\mathbf{V}$ are basis of eigenvectors associated to matrices $\mathbf{Y} \mathbf{Y}^{\prime}$ and $\mathbf{Y}^{\prime} \mathbf{Y}$, respectively. Using (A-3) and (A-4) we obtain the following equalities:

$$
\mathbf{Y} \mathbf{Y}_{T \times T}^{\prime}=\nu \cdot \mathbf{e}^{\prime} \mathbf{e} \cdot \nu^{\prime}=\mathbf{U}\left(\Lambda \Lambda^{\prime}\right) \mathbf{U}^{\prime}
$$

and

$$
\mathbf{Y}^{\prime} \mathbf{Y}_{N \times N}=\mathbf{e} \cdot \nu^{\prime} \nu \cdot \mathbf{e}^{\prime}=\mathbf{V}^{\prime}\left(\Lambda^{\prime} \Lambda\right) \mathbf{V}
$$

However, by definition there is only one non-zero eigenvalue equal to one, that is $[\Lambda]_{1,1}=1$ and $[\Lambda]_{t, x}=0, \forall t \neq 1$ and $x \neq 1$. Therefore, $\mathbf{Y}$ can be decomposed as

$$
\mathbf{Y}_{T \times N}=\mathbf{u}_{T \times 1} \cdot \mathbf{v}_{N \times 1}^{\prime}=\left(\frac{\nu}{\sqrt{\mathbf{e}^{\prime} \mathbf{e}}}\right)_{T \times 1} \cdot\left(\frac{\mathbf{e}}{\sqrt{\nu^{\prime} \nu}}\right)_{N \times 1}^{\prime}
$$

Finally, as we are only interested in relative prices, the fact that $\mathbf{e}$ is weighted by $\sqrt{\nu^{\prime} \nu}=1$ does not affect our problem. Figure 10, below, reports the age-specific labor productivity index by age, obtained using the singular value decomposition.

\section{A.3 Labor-augmenting technological progress}

The growth rate of the labor-augmenting technological progress from 1900 onwards is estimated using the usual formula derived from the Cobb-Douglas production function,

$$
\frac{\Delta A_{t}}{A_{t}} \approx \frac{1}{1-\alpha} \frac{\Delta y_{t}}{y_{t}}-\frac{\alpha}{1-\alpha} \frac{\Delta k_{t}}{k_{t}}-\frac{\Delta(L / N)_{t}}{(L / N)_{t}},
$$

\footnotetext{
${ }^{27}$ This step is not strictly necessary since the time component will capture this information.
} 


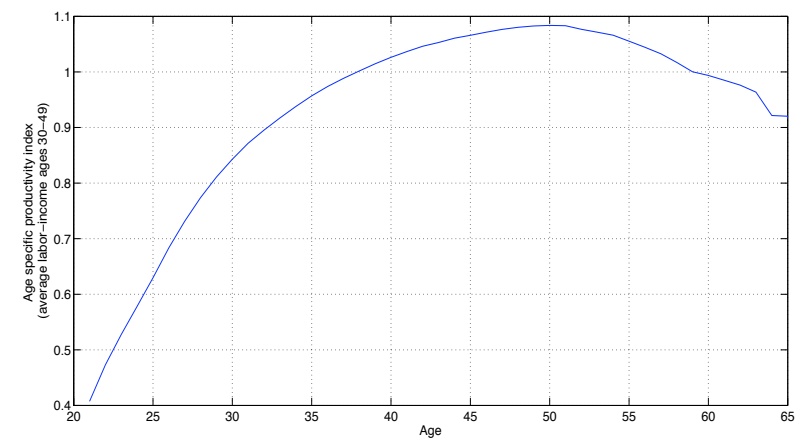

Figure 10: Spain: Estimated Age-Specific Labor Productivity Index

where $\alpha$ is the capital share, $y$ is the GDP per capita, and $k$ is the stock of capital per capita. The estimation of $A_{t}$ is split into three periods: 1900-1969, 1970-2008, 2009-. First, for the 1970-2008 period, we have complete information from the OECD database (www.oecd.org/statistics/productivity). Thus, we calculate: i) the stock of capital using the time series of "Gross Fixed Capital Formation" and the "Consumption of Fixed Capital", ii) the average rate of depreciation of capital from 1970 to $2008(\delta=4.85 \%)$, and iii) the capital share $(\alpha \approx 0.36) .{ }^{28}$ Second, the projection of labor productivity to the future (2009-) is the same as that of the European Policy Committee (2009). Third, for the period before 1970, we use the Spanish GDP per capita from Maddison (2006) and we take the stock of capital from Mas et al. (1995) and Cubel and Palafox (1997). Finally, we derive $A_{t}$ by combining the labor productivity, $\alpha$, our forecasted Spanish population, and our estimated total employment for the same period. Figure 11 shows our estimated $A_{t}$ from 1970 to 2040 .

\section{A.4 Public and private consumption profiles}

We assume that parents finance the consumption of their children up to the age at which they become economically independent. We assume that consumption is comprised of three main items: health $\{h\}$, education $\{e\}$, and others $\{o\}$, which can be financed publicly or privately. To calculate the equivalent adult consumer units (EAC) in expenditure $j$ at age $x$, we divide the consumption of the individual in expenditure $j$ at age $x$ by the mean consumption (others) of his/her parent in 2000 .

Let the empirical distribution function of children born in year $t-x$ from parents up to age $s$ be $F_{t-x}(s)=\sum_{z=T_{w}}^{s} \frac{N_{t-x, z}}{N_{t-x, 0}} \hat{f}_{t-x, z}$, where $s \in \mathcal{X}=\left\{T_{w}, \ldots, \Omega-1\right\}$. For notational convenience we split the set $\mathcal{X}$ into two meaningful demographic sets: working years $(\mathcal{L})$ and retirement years $(\mathcal{R})$.

\footnotetext{
${ }^{28}$ Our estimated values of $\delta$ and $\alpha$ are very similar to those obtained by Ríos-Rull (2001) $(\delta=4 \%, \alpha=0.36)$
} 


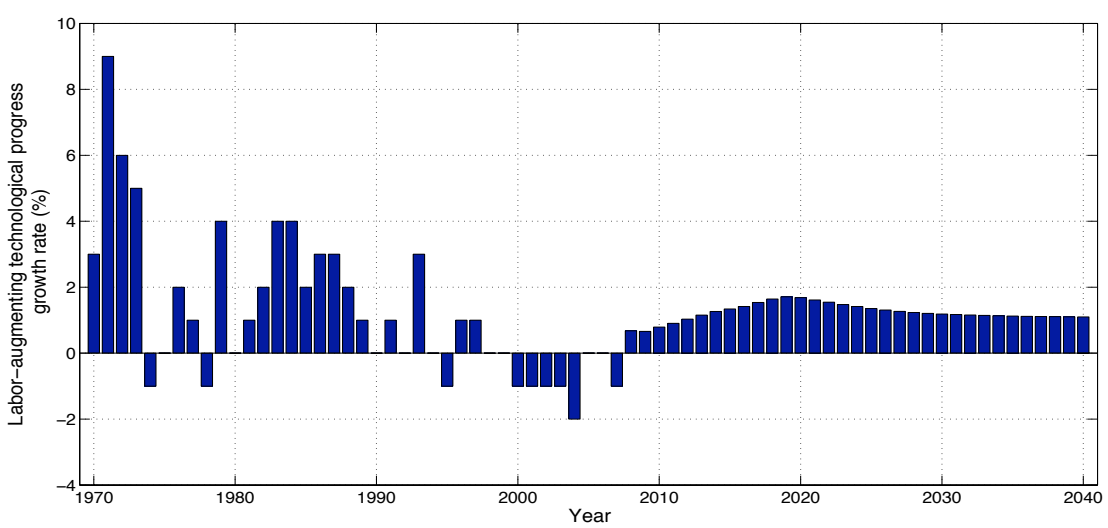

Figure 11: Growth rate of the labor-augmenting technological progress: Spain, 1970-2040.

Source: Author's calculations from different sources.

$$
\theta_{x}^{j}= \begin{cases}c_{t, x}^{j} / \int_{\mathcal{X}} c_{t, s+x}^{o} d F_{t-x}(s) & \text { if } 0 \leq x<T_{w}, \\ c_{t, x}^{j} / c_{t, s+x}^{o} & \text { if } x \in \mathcal{X} .\end{cases}
$$

We estimate EAC units for public expenditures on health, education, and others in relation to private consumption others.

$$
\tilde{\theta}_{x}^{j}= \begin{cases}g_{t, x}^{j} / \int_{\mathcal{X}} c_{t, s+x}^{o} d F_{t-x}(s) & \text { if } 0 \leq x<T_{w}, \\ g_{t, x}^{j} / c_{t, s+x}^{o} & \text { if } x \in \mathcal{X} .\end{cases}
$$

\section{A.5 Taxes profiles}

We assume that the government runs a balanced budget, in which payroll taxes finance a set $\mathbb{B}$ of contributory benefits (i.e., retirement, survivors, and maternity),

$$
\int_{\mathcal{X}} \sum_{j \in \mathbb{B}} b_{t, x}^{j} d N_{t}(x)=\tau_{t}^{s} \int_{\mathcal{X}} \omega_{t} A_{t} \epsilon_{x} d N_{t}(x),
$$

and taxes on production and income (corporate income tax and individual income tax) finance a set $\mathbb{I}$ of public consumptions, that is

$$
\begin{aligned}
\int_{\mathcal{X}} \sum_{j \in \mathbb{J}} g_{t, x}^{j} d N_{t}(x) & =\tau_{t}^{p} \int_{\mathcal{X}} \lambda_{t, x} c_{t, x} d N_{t}(x) \\
& +\int_{\mathcal{L}} \tau_{t, x}^{I}\left(\omega_{t} A_{t} \epsilon_{x}+b_{t, x}^{m}+r_{t}\left(a_{t, x}+h_{t, x}\right)\right) d N_{t}(x) \\
+ & \int_{\mathcal{R}} \tau_{t, x}^{I}\left(b_{t, x}^{r}+b_{t, x}^{w}+r_{t}\left(a_{t, x}+h_{t, x}\right)\right) d N_{t}(x)+\tau^{c} \frac{r_{t}+\delta}{1-\tau^{c}} K_{t}
\end{aligned}
$$




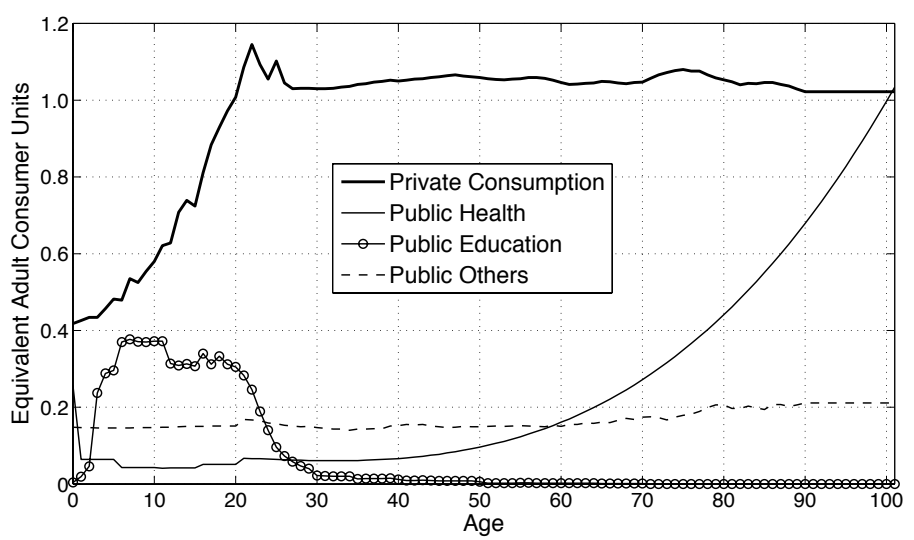

Figure 12: Equivalent Adult Consumer Units by Expenditure

Note: Private consumption (thick black solid line) is the sum of $\theta_{x}^{h}+\theta_{x}^{e}+\theta_{x}^{o}$. The public health profile (thin black solid line) has been extended up to age 100 using an exponential function, whereas the remaining public profiles are assumed constant from age 90 to age 100. Source: NTA Spain (2000), HMD and Eurostat.

In order to maintain a balanced budget over time, the government changes taxes on production whenever public consumption expenditures $(G)$ are not covered by taxes on income.

In Spain, the individual income tax is a progressive tax. Thus we assume the following progressive tax formula:

$$
\tau^{I}\left(T_{t, x}^{y}\right)=I_{a}+I_{b} \cdot\left(T_{t, x}^{y}-1\right),
$$

where $T_{x}^{y}$ is the taxable income at age $x$ relative to the net labor income at age 25 . Thus, if taxable income equals net labor income at age 25 , then the individual income tax rate is $I_{a}$ and the marginal tax rate is $I_{b}$.

The tax parameters $\left\{\tau^{c}, \tau^{I}\right\}$ have been chosen so as to replicate as closely as possible the items contained in the 2000 Spanish Government Budget in Table 2. The remaining taxes are endogenously determined. The production tax is calculated using Equation (A-10). Table 2 shows how the difference between actual taxes on production and imports of $11.46 \%$, and simulated taxes on production (in parenthesis) of $11.04 \%$, is only . $42 \%$ of the GDP. The difference between the actual and simulated social contributions is higher because it is calculated so as to finance the contributory pension benefits modeled (retirement, survivors, and maternity). Thus, we are modeling up to $62.50 \%$ of all social contributions.

\section{A.6 Contributory pension benefits profiles}

Social benefits in 2000 represented more than $12 \%$ of the Spanish GDP. Social benefits are comprised of contributory and non-contributory pensions, or $9.91 \%$ and $0.28 \%$ of GDP, respectively; unemployment, or $1.38 \%$ of GDP; and other social protections, or $0.52 \%$ of GDP. We have modeled contributory retirement and 
Table 5: Values for the fixed tax parameters in 2000

\begin{tabular}{lcr}
\hline & Parameter & Value \\
\hline Corporate Income Tax & $\tau^{c}$ & $9.6 \%$ \\
Individual Income Tax & $I_{a}$ & $1.80 \%$ \\
& $I_{b}$ & $3.84 \%$ \\
\hline
\end{tabular}

widowhood benefits based on the Spanish Social Security rules, as well as on contributory maternity benefits.

As with the tax parameters, the benefit parameters have been calibrated to match not only the percentage of the expenditure with respect to the GDP, but also each benefit age profile.

Table 6: Values for the fixed tax parameters in 2000

\begin{tabular}{lcr}
\hline & Parameter & Value \\
\hline Number of years of contribution & $N_{b}$ & 15 \\
Retirement benefit & $\pi_{r}$ & $53 \%$ \\
Maternity benefit & $\pi_{m}$ & $10 \%$ \\
\hline
\end{tabular}

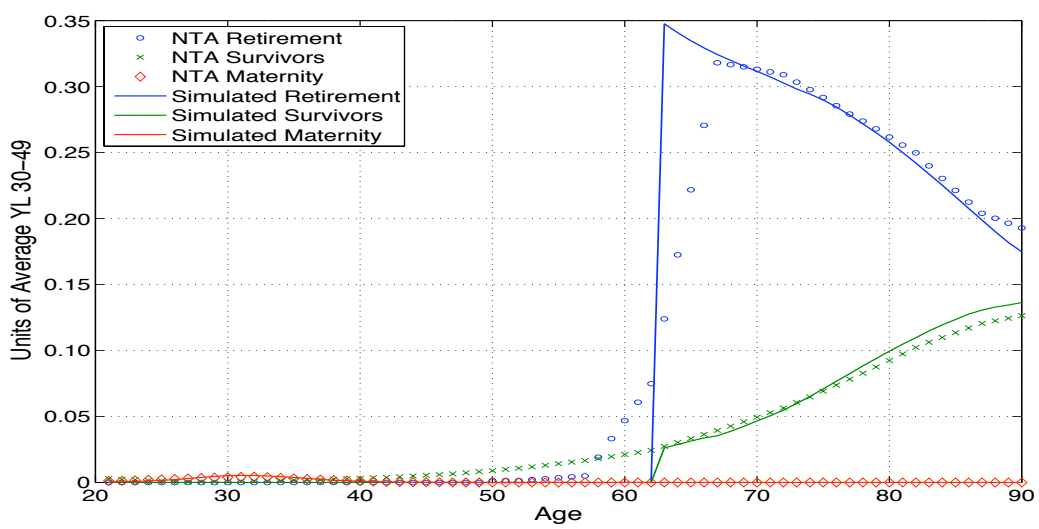

Figure 13: Spain, NTA and Simulated Public Benefits in 2000

Source: NTA Spain (2000), HMD and Eurostat.

\section{A.6.1 maternity benefit}

The maternity benefit is temporary and proportional to the (annual) salary. Let the fraction of the salary received by a parent of a recently born child be denoted 
by $\pi_{m}$. Thus, we model this benefit as a fraction of the salary of those people who have children during the current year.

$$
b_{t, x}^{m}=\pi_{m} \omega_{t} A_{t} \epsilon_{x}\left(1-u_{t, x}\right) \hat{f}_{t, x} \text { for } x \in \mathcal{X} .
$$

where $\hat{f}_{t, x}$ is the age-specific fertility rate of an individual of age $x$ in year $t .^{29}$

\section{A.6.2 retirement benefit}

The Spanish government runs an unfunded defined benefit pension plan. Retirement benefits after retirement depend on the (real) mean salary of the last $15\left(N_{b}\right)$ years. Moreover, retirement benefits are adjusted for inflation, thus after retirement (real) benefits remain constant. Then, the pension benefit formula applied in this model is as follows:

$$
b_{t, x}^{r}=\frac{\pi_{r}}{N_{b}} \sum_{z=T_{r}-N_{b}}^{T_{r}-1} \omega_{t-x+z} A_{t-x+z} \epsilon_{z}\left(1-u_{t-x+z, z}\right) \text { for } x \in \mathcal{R},
$$

where $T_{r}$ is the mean age at retirement and $\pi_{r}$ is the correction factor for early retirement.

\section{A.6.3 widowhood benefit}

Widow benefits are established as a proportion of the pension rights accumulated by the dead partner. The benefit is modeled in cohort terms as shown in Equation (A-14) below

$$
b_{t, x}^{w}=b_{t, x}^{r} \cdot \frac{l_{t-x+50,50}-l_{t, x}}{l_{t-x+50,50}} \text { for } x \in \mathcal{R} .
$$

where $l_{t, x}$ is the probability that an individual survives from birth to age $x$ in year $t$.

\section{A.7 Private Transfers}

We divide private transfers into transfers made within the household (intra-household), and transfers from one household to another (inter-household). The NTA database contains detailed information on transfers made to and received from members living in the same household; e.g., working children, spouses, and parents. Here, the only transfers modeled as intra-household correspond to (net) transfers made from parents to their children while they are younger than $T_{w}$ years old. Once their children have set up their own household, parents will continue making transfers to their children; however, these transfers will be then considered inter-household.

\section{A.7.1 Intra-household transfers}

In this model, parents pay for their children's consumption needs while they are younger than $T_{w}$ years old. The consumption of a child of age $x$ is assumed to be

\footnotetext{
${ }^{29}$ The age-specific fertility rate is truncated so that it aligns with the assumption that children do not make any decisions.
} 
a fraction $\theta_{x}$ of the adult's consumption (measured in units of EAC). Hence, the cost of childrearing for the head of household depends not only on the number of surviving children, but also on their ages. To simplify our notation, we have opted to summarize the number of EAC within a household whose head is $x$ years old in year $t$ using $\lambda_{t, x}$. Its mathematical expression is given by

$$
\lambda_{t, x}=1+\sum_{s=T_{w}}^{x} \theta_{x-s} \frac{l_{t-x+s, s}}{l_{t, x}} l_{t, x-s} \hat{f}_{t-x+s, s} I_{x-s<T_{w}} .
$$

where $I$ is an index function that takes a value of one when the inequality is satisfied and zero otherwise.

Equation (A-15) also takes into account the number of orphans who are raised within the cohort. This fact can easily be seen multiplying (A-15) by the size of the cohort. After some rearrangements, we derive that $\lambda_{t, x} N_{t, x}$ equals the size of the cohort, plus the total number of dependent children raised within the cohort, in EAC units, regardless whether their parents are alive or not; i.e., if they are orphans and or non-orphans. Moreover, Equation (A-15) guarantees that we are taking into account the whole population in EAC units by summing $\lambda_{t, x} N_{t, x}$ across age.

\section{A.7.2 Inter-household transfers}

We assumed that inter-household transfers are only received by children older than $T_{w}$. Then, let us define $o_{t, x}$ as the number of (adult) surviving offspring older than $T_{w}$ years old of an individual of age $x$ in year $t$; or, equivalently

$$
o_{t, x}=\sum_{s=T_{w}}^{x} \frac{N_{t-x+s, s} \hat{f}_{t-x+s, s}}{N_{t, x}} l_{t, x-s} \cdot I_{x-s \geq T_{w}}
$$

Multiplying (A-16) by the cohort size and summing across age gives the total number of people older than $T_{w}$ who still have a parent alive. Defining this variable with such detail is important for two reasons. First, the bequest received by any individual will depend on the number of siblings eligible to hold assets. Thus, the oldest offspring is more likely to receive bequests than her/his younger siblings when the life expectancy is low. On the other hand, if we assume that bequests are shared equally among siblings, we expect that the youngest sibling will be better off with longer life expectancies. The increase in consumption is bigger, the younger the individual who receives the bequests. Second, holding bequests constant, offspring who belong to big families receive smaller assets than those in smaller families.

\section{Bequests}

Here, rather than taxing the unintentional bequest at all ages and spreading it out among those who are $T_{w}$ years old or among members of the same cohort, we assume that surviving offspring inherit their parents' wealth. Then, the "expected" bequest by an individual at age $x$ in year $t$ is given by

$$
h_{t, x}=\sum_{s=T_{w}}^{x} \frac{N_{t-x, s} \hat{f}_{t-x, s}}{N_{t-x, 0}} \frac{q_{t, s+x}}{p_{t, x}} \frac{a_{t, s+x}}{o_{t, s+x}}+\frac{q_{t, x}}{p_{t, x}} a_{t, x} I_{x<2 \cdot T_{w}},
$$


where $q_{t, x}$ is the probability of dying between age $x$ and $x+1$ among cohort members alive at age $x, p_{t, x}$ is the probability of surviving between age $x$ and $x+1$ among cohort members alive at age $x$, and $a_{t, x}$ is the assets at age $x$ in year $t$. The second term of Equation (A-17) takes into account the fact that individuals under 42 years old, or $2 T_{w}$, cannot leave their stock of assets to their children.

Equation (A-17) says that the amount of bequest to be inherited is positively related to the parent's wealth and the parent's mortality risk, and negatively related to the number of siblings.

\section{Inter-vivos transfers}

According to actual Spanish NTA data, elderly parents are (net) financial supporters of their offspring, even when they are retired. An international comparison using NTA shows a similar result. In addition, countries where public transfers finance a greater proportion of the life cycle deficit at age 65 and over also have greater private downward transfers. In order to capture this last feature, we introduce an additional parameter, named $\psi_{t, x}$, with the following characteristics:

$$
\frac{\partial \psi}{\partial \mathrm{TG}}>0, \frac{\partial \psi}{\partial \mathrm{ABR}}<0
$$

For simplicity we assume that

$$
\psi_{t, x}=\frac{\pi \cdot \mathrm{TG}_{t, x}}{\mathrm{TG}_{t, x}+\mathrm{ABR}_{t, x}} \text { for } x \in \mathcal{R},
$$

where $\pi$ is an adjustment factor that we estimate to be close to 0.5 .

Finally, according to the data, we assume that the amount of money transferred from each elderly person to her or his children is proportional to the public pension benefits received (widowhood and retirement),

$$
\phi_{t, x}=-\psi_{t, s+x}\left(b_{t, s+x}^{s}+b_{t, s+x}^{r}\right) \text { for } x \in \mathcal{R} .
$$

which implies that workers $x \in\left\{T_{w}, \ldots, T_{r}-1\right\}$ in year $t$ will receive an expected transfer from their retired parents equal to

$$
\phi_{t, x}=\sum_{s=T_{w}}^{\Omega-1-x} \frac{N_{t-x, s} \hat{f}_{t-x, s}}{N_{t, 0}} \frac{l_{t, s+x}}{o_{t, s+x}} \psi_{t, s+x}\left(b_{t, s+x}^{s}+b_{t, s+x}^{r}\right) I_{s+x \geq T_{r}} .
$$

Thus, Equation (A-21) implies that children with older parents will consume more than children with younger parents, assuming the other variables are equal. This is because the transfer of wealth is greater for children with older parents than for children with younger parents, since the latter group receive inter-vivos transfers later in life.

\section{B Computational Details}

To simplify notation, age and time indexes are removed, while the next period is denoted by "'". In the following, we use the notation $\mathbf{R}_{+}$to represent $\mathbf{R}^{+} \cup\{0\}$. 


\section{B.1 Household Problem}

The head of the household at age $x \in \mathcal{X}$ aims in year $t \in \mathcal{T}=\left\{t_{0}, t_{0}+1, \ldots, T\right\}$ to maximize her expected utility by choosing the optimal consumption and assets in period $t+1$. The Bellman equation for the head of the household reads as

$$
v(t, x, a \mid A)=\max _{c, a^{\prime}}\left\{\lambda u(c)+\beta p v\left(t+1, x+1, a^{\prime} \mid A^{\prime}\right)\right\},
$$

with $\beta$ equal to 0.99 and a relative risk aversion coefficient $(\sigma=1.76)$ associated to an upper middle-income country (Reinhart et al., 1996).

Subject to

$$
a^{\prime}= \begin{cases}(1+\tilde{r})(a+h)+\left(1-\tau^{i}\right)\left(1-\tau^{s s}\right) y_{l}+b^{m}+\phi-\left(1+\tau^{p}\right) \lambda c & \text { if } x \in \mathcal{L}, \\ (1+\tilde{r})(a+h)+\left(1-\tau^{i}\right) \sum_{\mathbb{B}-\{m\}} b+\phi-\left(1+\tau^{p}\right) \lambda c & \text { if } x \in \mathcal{R},\end{cases}
$$

and the boundary conditions

$$
c>0, a \geq 0, \text { with } a_{\cdot, T_{w}}=a_{\cdot, \Omega}=0 .
$$

where $\tilde{r}$ is the after-tax (real) interest rate, $\lambda$ is the number of equivalent adult consumers in the household, $p_{t, x} \in[0,1)$ is the probability of surviving to age $x+1$ in year $t+1$ conditional on being alive at age $x$ in year $t, h$ is the bequest received, $\tau^{i}$ is the personal income tax rate, $\tau^{s s}$ is the payroll tax rate, $\tau^{p}$ is the consumption tax rate, $y_{l}$ is the average gross salary by age (or $y_{l}=\omega A \epsilon(1-u)$ ), $b$ is the public benefits received (maternity, retirement, widowhood), $\phi$ is other (net) interhousehold transfers received, $a$ denotes asset holdings, and $A$ is the laboraugmenting technological progress.

Let define $G\left(a, a^{\prime} \mid I\right)$ as the function of total amount of consumption goods obtainable for any combination of assets held at any $t$ and $t+1$, given the information $I$ at $t$, which depends upon the age of the individual and other time dependent and independent variables $\left\{r, \omega, h, u, A, \lambda, \epsilon, \tau^{i}, \tau^{s s}, \tau^{p},\left\{b^{j}\right\}_{j \in \mathbb{B}}, \phi\right\} \in \mathbf{I}$, then $\mathbf{I} \subset \mathcal{X} \times \mathbf{R}_{+}^{12} \times \mathbf{R}$. That is,

$$
\begin{aligned}
c= & G\left(a, a^{\prime} \mid I\right)= \\
& \begin{cases}\frac{1}{\left(1+\tau^{p}\right) \lambda}\left((1+\tilde{r})(a+h)-a^{\prime}+\left(1-\tau^{i}\right)\left(1-\tau^{s s}\right) y_{l}+b^{m}+\phi\right) & \text { if } x \in \mathcal{L}, \\
\frac{1}{\left(1+\tau^{p}\right) \lambda}\left((1+\tilde{r})(a+h)-a^{\prime}+\left(1-\tau^{i}\right) \sum_{\mathbb{B}-\{m\} b}+\phi\right) & \text { if } x \in \mathcal{R} .\end{cases}
\end{aligned}
$$

Let define the set $C \subset \mathbf{R}_{+} \times \mathbf{R}_{+}$as the region of pairs $\left(a, a^{\prime}\right) \in \mathbf{R}_{+}^{2}$ where consumption is nonnegative; that is, $C=\left\{\left(a, a^{\prime}\right) \in \mathbf{R}_{+}^{2}: G\left(a, a^{\prime} \mid I\right) \geq 0\right.$, for any given $\left.I\right\}$. It is easy to prove that $C$ is a convex set. Now, using (A-25) let us rewrite the Bellman equation as

$$
v(t, x, a \mid A)=\max _{a^{\prime}}\left\{\lambda u\left(G\left(a, a^{\prime} \mid I\right)\right)+\beta p v\left(t+1, x+1, a^{\prime} \mid A^{\prime}\right)\right\} .
$$

The algorithm operates on (A-26) for all individuals in each year up to the point at which the model converges. The algorithm involves the following steps:

1. Define a time-independent grid for assets, with $\left\|a_{i+1}-a_{i}\right\|$ sufficiently small,

$$
G^{a}=\left\{a_{1}=0, a_{2}, a_{3}, \ldots, a_{n}\right\}
$$


where $a_{n}$ is the maximum realization of assets weighted by units of effective labor.

2. Define the correspondence $f: G^{a} \rightarrow G^{a}$ of optimal combinations of assets in $t$ and $t+1$ at age $x$.

$$
f\left(a_{k} \mid I, A^{\prime}\right)=a_{j}^{*}=\arg \max _{a_{j}}\left\{\lambda u\left(G\left(a_{k}, a_{j} \mid I\right)\right)+\beta p v\left(t+1, x+1, a_{j} \mid A^{\prime}\right)\right\},
$$

where $I \in \mathbf{I}$ and $A^{\prime} \in \mathbf{R}^{+}$is the productivity in year $t+1$. Note that $f$ has a one-to-one correspondence given that $C$ is a convex set and $u(\cdot)$ is strictly concave.

3. Calculate the set $\left\{\left(a_{k}, f\left(a_{k} \mid I, A^{\prime}\right)\right)\right\}_{k=1}^{n} \in C^{2 n}$ of all possible optimal asset pairs for the household head in year $t$. Evaluate Equation (A-26) by introducing all optimal asset pairs. Repeat this process for the entire life cycle of the head of the household.

4. Repeat step 3 for all households.

5. Given the initial boundary conditions, we know that wealth at the beginning of adulthood is zero, or $a_{t, T_{w}}=a_{1} \in G^{a}, \forall t \in \mathcal{T}$. Therefore, given all information sets over the life cycle of the head of the household and Equation (A-28), we iterate forward on age and time to get the optimal path of asset holdings.

6. Repeat step 5 for all individuals.

\section{B.2 Aggregate Model}

In this model, the equilibrium price vector is numerically obtained using a Tatonnement; see Judd (1998).

The simulation strategy was to calculate the demand and supply of capital at all times for a given vector of interest rates $\left\{r_{t}^{i}\right\}_{t=t_{0}}^{T}$, with $T$ sufficiently large and $i$ denoting the $i$-th iteration, such that there is no excess of demand of capital at any time. The information set prior to the simulation is a vector of time-invariant parameters, demographic characteristics, and degrees of technological progress for $t \in \mathcal{T}$. In order to guarantee the existence of an equilibrium, the phase-in (out) period begins (finishes) with a stable population 200 years before (after) the period being analyzed, so that the economy before and after the demographic transition is in a steady-state equilibrium. The algorithm is divided into the following seven steps:

1. Choose a dumping factor of $\xi=0.2$ and a tolerance $\epsilon$ equal to 0.01 .

2. Make an initial guess $\left\{R_{t}^{0}\right\}_{t=t_{0}}^{T}$, where $R_{t}^{i}$ is equal to $r_{t}^{i}+\delta$ for all $i \in \mathbf{N}$, in which the initial and final steady-state interest rates are included.

3. Given the initial guess, use a Cobb-Douglas production function to calculate its associated salary over time in units of effective labor

$$
\omega_{t}^{i}=(1-\alpha)\left(\frac{R_{t}^{i}}{\alpha}\right)^{\frac{\alpha}{\alpha-1}}, \forall t \in \mathcal{T} .
$$


4. Compute the household problem and aggregate assets across all household heads to determine the capital stock per units of effective labor

$$
\kappa_{t}=\frac{\sum_{x=T_{w}}^{\Omega-1} a_{t, x} N_{t, x}}{\sum_{x=T_{w}}^{T_{r}-1} A_{t} \epsilon_{x}\left(1-u_{t, x}\right) N_{t+1, x+1}}, \forall t \in \mathcal{T}
$$

5. Next, determine the marginal product of capital resulting from (A-30), that is

$$
r_{t}^{n}+\delta=\alpha \kappa_{t}^{\alpha-1}, \forall t \in \mathcal{T} .
$$

6. If $\left\|\mathbf{r}^{i}-\mathbf{r}^{n}\right\|<\epsilon$ then STOP.

7. Otherwise, compute a new vector of interest rates and salaries

$$
\begin{aligned}
r_{t}^{i+1} & =(1-\xi) r_{t}^{i}+\xi r_{t}^{n}, \\
\omega_{t}^{i+1} & =(1-\alpha)\left(\frac{r_{t}^{i+1}+\delta}{\alpha}\right)^{\frac{\alpha}{\alpha-1}}, \forall t \in \mathcal{T} .
\end{aligned}
$$

8. Calculate a new set of public benefits $\left\{b_{t, x}^{i}\right\}_{i \in \mathbb{B}}$ and public goods $\left\{g_{t, x}^{j}\right\}_{i \in \mathbb{J}}$ for all $x \in \mathcal{X}$ and $t \in \mathcal{T}$ according to equations (A-8)-(A-14).

9. Calculate payroll taxes $\left(\left\{\tau_{t}^{s s}\right\}_{t \in \mathcal{T}}\right)$ and consumption tax rates $\left(\left\{\tau_{t}^{p}\right\}_{t \in \mathcal{T}}\right)$ such that (A-9) and (A-10) are satisfied.

10. Compute the set of inter-household transfers: bequests and inter-vivos transfers according to Equations (A-17) and (A-20)-(A-21), respectively.

Then go to step 4. 


\section{Data Sources}

Table 7: Data sources used in National Transfers Accounts age profiles

\begin{tabular}{|c|c|}
\hline Age profiles & Data source \\
\hline \multicolumn{2}{|l|}{ Lifecycle deficit (LCD) } \\
\hline \multicolumn{2}{|l|}{ Private consumption } \\
\hline Private health consumption $(\mathrm{CF})$ & INE: Encuesta Continua de Presupuestos Familiares (ECPF), 2000 \\
\hline Private education $(\mathrm{CFH})$ & INE: ECPF, 2000 \\
\hline Private housing (CFR) & INE: ECPF, 2000 \\
\hline Other private consumption (CFX) & INE: ECPF, 2000 \\
\hline \multicolumn{2}{|l|}{$\begin{array}{l}\text { Public consumption } \\
\text { Pull }\end{array}$} \\
\hline Public health consumption (CG) & MSC: Estadística del Gasto Sanitario Público, 2002 \\
\hline \multirow[t]{3}{*}{ Public education (CGH) } & MEC: Estadística de Enseñanzas no Universitarias \\
\hline & MEC: Estadística del Gasto Público en Educación \\
\hline & INE: Estadística de la Enseñanza Superior en España \\
\hline Other public consumption (CGX) & Per capita \\
\hline Labour Income (YL) & Eurostat: EU Household Panel, 2000 \\
\hline Self-employed (YLS) & Eurostat: EU Household Panel, 2000 \\
\hline Earnings (YLE) & Eurostat: EU Household Planel, 2000 \\
\hline \multicolumn{2}{|l|}{ Public transfers (outflows) } \\
\hline Social Security contributions & Eurostat: EU Household Panel, 2000 \\
\hline Personal income tax & Eurostat: EU Household Panel, 1998 \\
\hline Capital tax & Eurostat: EU Household Panel, 2000 \\
\hline Value-added tax (VAT) & INE: ECPF, 2000 \\
\hline Property tax & INE: ECPF, 2000 \\
\hline Excise taxes (except tobacco) & INE: ECPF, 2000 \\
\hline Excise tax on tobacco & INE: ECPF, 2000 \\
\hline \multicolumn{2}{|l|}{ Public transfers (inflows) } \\
\hline $\begin{array}{l}\text { Contributory pensions (retirement, disability, } \\
\text { widowhood, survivors) }\end{array}$ & MTAS: Informe Estadístico del INSS, 2000 \\
\hline $\begin{array}{l}\text { Non-contributory pensions (retirement, disability); } \\
\text { unemployment and temporary disability benefits }\end{array}$ & MTAS: Anuario de Estadísticas Laborales y Asuntos Sociales, 2000 \\
\hline Social Security family benefits & MTAS: Informe Estadstico del INSS, 2000 \\
\hline Health benefits (hospital and primary care, pharmaceuticals) & MSC: Encuesta Nacional de Salud, 1997 \\
\hline Education expenditure & MEC: Estadística de Enseñanzas no Universitarias; \\
\hline & $\begin{array}{l}\text { MEC: Estadística del Gasto Público en Educación; } \\
\text { INE: Estadística de la Enseñanza Superior en España }\end{array}$ \\
\hline Long-term care & $\begin{array}{l}\text { CIS: Encuesta sobre la soledad de las personas } \\
\text { mayores, } 1998\end{array}$ \\
\hline \multicolumn{2}{|l|}{ Private transfers } \\
\hline Interhousehold transfers (inflows) & Eurostat: EU Household Panel, 2000 \\
\hline Interhousehold transfers (outflows) & INE: ECPF, 2000 \\
\hline Intrahousehold transfers (in/outflows) & $\begin{array}{l}\text { Eurostat: EU Household Panel, } 2000 \\
\text { INE: ECPF, } 2000\end{array}$ \\
\hline \multicolumn{2}{|l|}{ Asset Based Reallocations } \\
\hline Asset income profiles & Eurostat: EU Household Panel, 2000 \\
\hline Interest profiles & Eurostat: EU Household Panel, 2000 \\
\hline
\end{tabular}

Note: See Lee and Mason (2010a) and the chapter for Spain for further details about the methodology and data sources. 